\title{
Percutaneous coronary intervention: recommendations for good practice and training
}

\author{
K D Dawkins, T Gershlick, M de Belder, A Chauhan, G Venn, P Schofield, D Smith, J Watkins, \\ H H Gray, Joint Working Group on Percutaneous Coronary Intervention of the British \\ Cardiovascular Intervention Society and the British Cardiac Society
}

Heart 2005;91(Suppl VI):vi1-vi27. doi: 10.1136/hrt.2005.061457

\section{EXECUTIVE SUMMARY}

Cardiologists undertaking percutaneous coronary intervention (PCI) are excited by the combination of patient and physician satisfaction and technological advance occurring on the background of the necessary manual dexterity. Progress and applicability of percutaneous techniques since their inception in 1977 have been remarkable; a sound evidence base coupled with the enthusiasm and ingenuity of the medical device industry has resulted in a sea change in the treatment of coronary heart disease (CHD), which continues to evolve at breakneck speed.

This is the third set of guidelines produced by the British Cardiovascular Intervention Society and the British Cardiac Society. ' ${ }^{2}$ Following the last set of guidelines published in 2000 , we have seen $\mathrm{PCl}$ activity in the UK increase from 33652 to 62780 (87\% in four years) such that the $\mathrm{PCl}$ to coronary artery bypass grafting ratio has increased to $2.5: 1$. The impact of drug eluting stents has been profound, and the Department of Health is investigating the feasibility of primary $\mathrm{PCl}$ for acute myocardial infarction. Nevertheless, the changes in the structure of National Health Service funding are likely to focus our attention on cost effective treatments and will require physician engagement and sensitive handling if we are to continue the rapid and appropriate growth in our chosen field. ${ }^{3}$

It is important with this burgeoning development now occurring on a broad front (in both regional centres and district general hospitals) that we maintain our vigilance on audit and outcome measures so that standards are maintained for both operators and institutions alike. This set of guidelines includes new sections on training, informed consent, and a core evidence base, which we hope you will find useful and informative.

Keith D Dawkins

President, British Cardiovascular Intervention Society (20002004)

Huon H Gray

President, British Cardiac Society (2003-2005)

$\mathrm{P}$ ercutaneous coronary intervention (PCI) is now the most common procedure used in the invasive treatment of the patient with coronary heart disease (CHD). In the UK, the number of patients treated by PCI exceeded the number of those treated with surgical revascularisation for the first time in $1997 .{ }^{4}$ The ratio of PCI to coronary artery bypass grafting (CABG) had increased to 2.5:1 by 2004 .

Since the introduction of PCI by Gruentzig et al in 1977, the technology has developed rapidly through several phases. Simple balloon angioplasty became prevalent during the period 1977 to 1987. Adjunct balloon angioplasty, including atherectomy and laser assisted angioplasty, followed between 1988 and 1992, after which the use of intracoronary stents has increased progressively from 1993 until the present. The most recent British Cardiovascular Intervention Society (BCIS) audit figures for 2004 indicate that stents were used in $93.4 \%$ of patients (range between institutions $71-100 \%$ ). ${ }^{4}$ In 2002, the fourth important development in PCI occurred, namely, the introduction of the drug eluting stent, implanted in 53\% of UK PCI patients during 2004. These devices are likely to increase further the applicability of PCI to a wider range of lesion subsets, with the prospect of modifying the restenotic response to stent implantation. The first National Institute for Health and Clinical Excellence (NICE) appraisal of these drug eluting stents published in 2003 suggested that the decision to implant a drug eluting stent should be based on the anatomy of the target lesion ${ }^{6}$; submissions are being prepared for the second NICE appraisal on intracoronary stents due in March 2006.

In a field where technology is developing rapidly, it is important for centres undertaking such procedures to be appropriately equipped, for staff to be competent, and for case selection to be matched to the skill of the operators, who in turn are supported by a sound evidence base. In the UK, a national PCI dataset has been collected through BCIS since 1988. These data have confirmed that PCI is safe, with a procedure related mortality of $0.56 \%$ (range $0-2.2 \%$ ) in 2004 . Independent data collection by the National Confidential Enquiry into Patient Outcome and Death (NCEPOD) have confirmed the BCIS figures with a mortality of $0.87 \%$ when all UK deaths were collected for a 12 month period during 1998/9. ${ }^{7}$ Nevertheless, from time to time the outcomes of individual operators may fail to match those of their peers, and it is important that these outliers be identified, counselled, and if necessary retrained. Institutional clinical governance should allow the identification of both individual

\footnotetext{
Abbreviations: ACC, American College of Cardiology; ACS, acute coronary syndromes; AHA, American Heart Association; ARSAC, Administration of Radioactive Substances Advisory Committee; BCIS, British Cardiovascular Intervention Society; BCS, British Cardiac Society; CABG, coronary artery bypass grafting; CCAD, Central Cardiac Audit Database; $\mathrm{CHD}$, coronary heart disease; $\mathrm{Cl}$, confidence interval; DICOM, digital imaging and communications in medicine; $\mathrm{DoH}$, Department of Health; FFR, fractional flow reserve; IVUS, intravascular ultrasound; LMS, left main stem; MACE, major adverse cardiac events; MHRA, Medicines and Healthcare products Regulatory Agency; MI, myocardial infarction; MR, moderate release; NCDR, National Cardiovascular Data Registry; NCEPOD, National Confidential Enquiry into Patient Outcome and Death; NICE, National Institute for Health and Clinical Excellence; NSCAG, National Specialist Commissioning Advisory Group; NSF, National Service Framework; PCI, percutaneous coronary intervention; PTCA, percutaneous transluminal coronary angioplasty; SERNIP, Safety and Efficacy Register for New Interventional Procedures; SR, slow release; TLR, target lesion revascularisation
} 
and system failures through local audit and data collection, which can then be compared with the national dataset. Developments in the Central Cardiac Audit Database (CCAD) (www.ccad.org.uk) will allow a patient to be tracked through his or her individual cardiac journey, from birth until death, while providing the means for comparison of patient, operator, or institution specific outcome data with the national figures.

The BCS and the BCIS have previously produced two sets of guidelines for the best practice of coronary angioplasty in 1996 and 2000. ${ }^{12}$ Since the last guidelines were published, changes in both technology and health care delivery have occurred such that this new set of guidelines is timely. Many of the goals outlined in the National Service Framework for coronary heart disease (NSF CHD) ${ }^{8}$ have been realised. Open access chest pain clinics have resulted in the more rapid assessment of the patient with CHD. The patient with CHD is now more often under the care of a specialist cardiologist who is familiar with the evidence base for the appropriate investigation and treatment of this group of patients. Similarly the coronary care unit is more often managed by a cardiologist, such that patients are treated on care pathways according to agreed guidelines and protocols. The redefinition of acute MI, together with the consensus statements on the appropriate management of both ST elevation and non-ST elevation MI, has resulted in a dramatic increase in the invasive investigation of these patients. ${ }^{9-11}$ Cardiac catheterisation is an integral step in the assessment of patients with acute coronary syndromes (ACS); furthermore, invasive investigation has been brought forward in the natural history of the condition, particularly in patients with positive markers for risk (for example, increased troponin). The concept of "diagnostic catheterisation query proceed to PCI" (follow on or ad hoc PCI) has become common place and now accounts for more than $50 \%$ of the procedures in many centres.

PCI rates have increased progressively in the UK (fig 1); between 2003 and 2004 there was a 17.4\% in-year increase. In 2004, 62780 PCI procedures were undertaken in the UK or

\begin{tabular}{|c|c|}
\hline \multicolumn{2}{|l|}{ Guide to cited websites } \\
\hline Website & URL \\
\hline $\begin{array}{l}\text { Academy of Medical Royal } \\
\text { Colleges }\end{array}$ & www.aomrc.org.uk \\
\hline British Cardiac Society & www.bcs.com \\
\hline $\begin{array}{l}\text { British Cardiovascular Intervention } \\
\text { Society }\end{array}$ & www.bcis.org.uk \\
\hline British Heart Foundation & www.bhf.org.uk \\
\hline $\begin{array}{l}\text { Coronary Heart Disease Audit } \\
\text { supported by the Central } \\
\text { Cardiac Audit Database }\end{array}$ & www.ccad.org.uk \\
\hline $\begin{array}{l}\text { Department for Environment, } \\
\text { Food and Rural Affairs }\end{array}$ & www.defra.gov.uk \\
\hline $\begin{array}{l}\text { Department of Health } \\
\text { Health Protection Agency, } \\
\text { Radiation Protection Division }\end{array}$ & $\begin{array}{l}\text { www.dh.gov.uk } \\
\text { www.hpa.org.uk/radiation/ }\end{array}$ \\
\hline Medical Research Council & www.mrc.ac.uk \\
\hline $\begin{array}{l}\text { Medicines and Healthcare } \\
\text { products Regulatory Agency }\end{array}$ & www.mhra.gov.uk \\
\hline $\begin{array}{l}\text { National Confidential Enquiry } \\
\text { into Patient Outcome and Death }\end{array}$ & www.ncepod.org.uk \\
\hline $\begin{array}{l}\text { National Coordinating Centre for } \\
\text { Health Technology Assessment }\end{array}$ & www.ncchta.org \\
\hline $\begin{array}{l}\text { National Institute for Health and } \\
\text { Clinical Excellence }\end{array}$ & www.nice.org.uk \\
\hline $\begin{array}{l}\text { National Specialist Commissioning } \\
\text { Advisory Group }\end{array}$ & $\begin{array}{l}\text { www.advisorybodies.doh.gov.uk, } \\
\text { NSCAG/ }\end{array}$ \\
\hline $\begin{array}{l}\text { New \& Emerging Applications of } \\
\text { Technology }\end{array}$ & www.neatprogramme.org.uk \\
\hline Royal College of Physicians & www.rcplondon.ac.uk \\
\hline
\end{tabular}

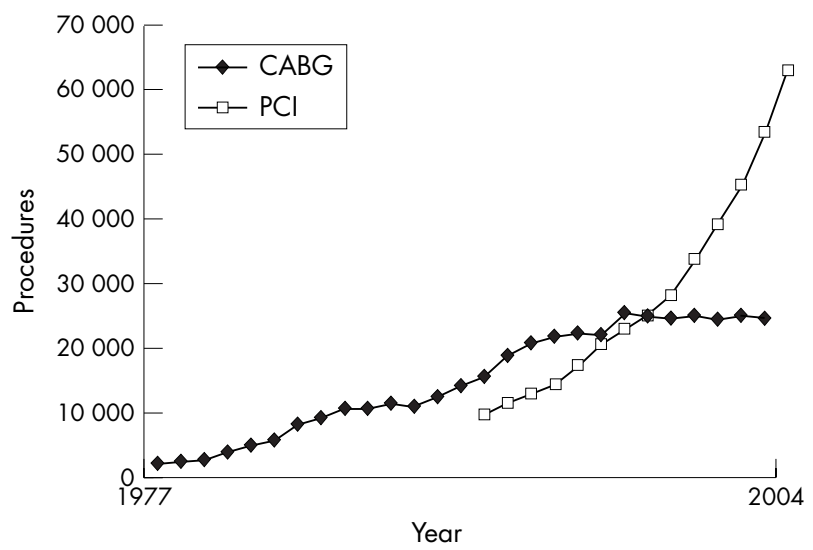

Figure 1 Isolated coronary artery bypass grafting (CABG) and percutaneous coronary intervention (PCI) in the UK. Source: Society of Cardiothoracic Surgeons of Great Britain, British Cardiovascular Intervention Society.

1050/million population. Although the majority of PCI in the UK is still undertaken in tertiary centres with on-site surgery, $15 \%$ of procedures were performed in centres without on-site surgery in 2003. The concept of delivering cardiac care through a local clinical network has gained momentum as a result of support from the DoH. Representatives from the DoH, BCS, and BCIS have developed guidelines for additional PCI centres within clinical networks, which will have strong links with their local surgical centre. ${ }^{4}$ PCI will be further expanded on two fronts: within the existing surgical centres; and with the development of new PCI centres in limited numbers of district general hospitals that can fulfil the institutional and operator standards. It is important that a common standard be applied across these two types of PCI centres if two levels of service provision are to be avoided. If quality is to be maintained the relationship with our cardiac surgical colleagues remains of paramount importance.

This set of guidelines aims at addressing these issues and includes sections on standards, peer review, training, surgical issues, informed consent, appraisal, future developments, and a core evidence base.

\section{STANDARDS \\ Institutions}

Although a routine procedure, PCI requires an experienced multidisciplinary team that can provide high quality care throughout the hospital stay. Areas of importance include the preprocedural assessment (including the consent process), the intervention itself, postprocedural recovery, and rehabilitation. For PCI to be regarded as "routine", previous guidelines have deemed it necessary to specify a minimum annual number of individual and institutional cases. The complication rate and the volume of procedures performed in an institution per annum are clearly related: morbidity and mortality in high volume centres are lower than in low volume centres. In the guidelines published in 2000, 200 procedures per annum was the standard, which is in accord with the most recent American College of Cardiology (ACC)/ American Heart Association (AHA) guidelines published in $2001 .{ }^{12}$ Institutional numbers have not been addressed in the most recent European Guidelines for Percutaneous Coronary Interventions published by the European Society of Cardiology in 2005. ${ }^{13}$ Despite the somewhat arbitrary cut off, the Committee favours maintaining this minimum acceptable institutional number of procedures, while encouraging individual centres to increase activity to a minimum of 400 procedures per annum, as some data suggest 
that quality can be further improved if a centre performs at this higher level of activity. Centres performing fewer than 200 procedures per annum should be encouraged to have a robust plan showing how these numbers will be increased in the future to achieve the minimum standard. In 1993, 10 of 42 NHS units $(24 \%)$ in the UK were undertaking fewer than 200 PCI procedures per annum but this had fallen to four of 77 (5\%) by 2004.

With the increasing number of cardiac catheterisation laboratories being installed in district general hospitals, which will mainly be performing diagnostic coronary arteriography, it is anticipated that the case mix in tertiary units will change in favour of PCI. To provide continuous cover by experienced interventional cardiologists, a typical centre will require a minimum of four and ideally six such specialists. If they are all to maintain their individual minimum numbers, as well as selected operators undertaking a training function (see below), a typical tertiary centre will have to perform a minimum of $500-800$ procedures per annum.

\section{Operators}

A successful interventional cardiologist requires a combination of manual dexterity and clinical judgement. Emphasis on the practicalities of the technique and procedural numbers, in the absence of teaching in relation to overall patient assessment, the limitations in the technology, the risk to benefit ratio, and the role of surgical revascularisation, is a major shortfall in some training programmes: the skilful interventional cardiologist lacking in clinical judgement will not best serve his or her patients.

It is axiomatic that the maintenance of the practical skills necessary for interventional cardiology requires a minimum number of procedures per annum to maintain those skills. Nevertheless, the Committee appreciates that the number of procedures required to be performed by an individual operator yearly to maintain competence is both arguable and arbitrary. Furthermore, it is difficult to find convincing support in the literature to favour high volume operators, as it is likely that these operators will be treating a more complex case mix than their low volume colleagues. The previous guidelines recommended a minimum of 75 procedures a year for independent operators. The Committee felt that this minimum number remains appropriate, while encouraging operators working at this low level to develop a strategy for increasing their own activity to 150 procedures a year or more. Acute complications during PCI are uncommon but may require prompt and appropriate treatment to avoid an unfavourable outcome. It seems probable that an operator undertaking fewer than one to two PCI procedures a week will not be sufficiently skilled to respond appropriately in an emergency situation.

Despite a guideline number being published there still sometimes seems to be confusion regarding interpretation. The commonly raised queries should be clarified by the following points:

- The current guidelines suggest that a minimum of 75 PCI procedures per operator per year is required to maintain competence as an independent operator-that is, one who can decide on PCI as appropriate management, plan the strategy, and perform the PCI without consulting any other operator, "buddy", mentor, or trainer.

- An operator may continue to perform fewer than 75 PCI procedures per annum providing he or she is fully mentored-that is, cases are reviewed together with the mentor or buddy and the management strategy is agreed beforehand, and providing the mentor or buddy is available in the catheterisation laboratory throughout the procedure to offer advice or assistance.

- For those independent operators who have fulfilled the guideline of 75 procedures a year for the previous two years and who are then absent from practice for less than six months (for example, due to illness or pregnancy) no additional training would be required. If the period of absence exceeds six months but is less than two years then a buddy system of $20-50$ procedures is advised (proportional to the period of absence exceeding six months) before the operator becomes fully independent again. Individual operators may feel that it is appropriate to arrange a buddy system in certain circumstances when the absence has been less than six months.

- Those operators who have been fully trained but who have not undertaken procedures for two years or more and are now wishing to re-start PCI should perform at least 150 procedures with a mentor, with 110 as first operator, either at the surgical centre or with the mentor coming to the new site before the operator should start to operate independently at the new site. The designated mentor should formally assess the ability, aptitude, and clinical judgement of the new operator.

- Cardiologists on the Specialist Register who have never been fully trained in PCI and who wish to start PCI should undergo full formal PCI training (see section 4. Training).

- Individual cardiologists who undertake PCI on multiple sites are responsible for justifying the aggregate of their PCI numbers across sites as part of the individual audit process.

\section{Facilities}

A centre performing PCI requires at least one cardiac catheterisation laboratory. Additional laboratories, if available, will provide backup for the inevitable equipment failures; alternatively, a backup high resolution portable fluoroscopy unit should be available for centres with a single catheterisation laboratory. A dedicated laboratory for cardiac procedures is likely to have a small enough image intensifier to allow for a wide variety of angulation, while maintaining table manoeuvrability and access to the patient. A high resolution digital imaging chain in one or two planes, with freeze frame, zoom, road mapping, and playback facilities, is desirable. Contemporary archiving is usually on compact disk in a digital imaging and communications in medicine (DICOM) compatible format, which should be stored and accessible for a minimum of eight years. PCI centres remote from surgical or tertiary centres should have facilities for real time image transfer to facilitate discussion and advice in individual cases.

Physiological measurements including accurate pressure recording and display of the waveforms on multiple simultaneous channels, together with display and recording of a range of ECG lead configurations, are also required. All patients who have received sedation must be monitored for oxygen saturation throughout the procedure.

Staff should be aware of the latest guidelines on radiation protection. ${ }^{14}$ The representative of the Radiation Protection Officer, usually a radiographer, should ensure that all staff working in the cardiac catheterisation laboratory comply with appropriate monitoring and that lead screens, aprons, glasses, and other methods of radiation shielding are always available and used appropriately. Each PCI centre should develop a robust capital and revenue funding stream for radiation protection equipment. Systems should be in place to track individual patients who have received large lifetime radiation dosing as a consequence of undergoing multiple 
procedures (which may include diagnostic, interventional, and electrophysiological procedures in the same patient).

Full resuscitation facilities including a defibrillator, intraaortic balloon counterpulsation, and an anaesthetic backup must be readily available in any catheterisation laboratory undertaking PCI. Biochemistry, haematological, and blood transfusion laboratories should be immediately accessible. Facilities for monitoring anticoagulation (for example, activated clotting time) should be available in the catheterisation laboratory.

A wide range of disposable angioplasty equipment including guiding catheters, guidewires, balloons, and stents must be available at all times, and a satisfactory method of inventory and stock control is mandatory. Additional technology including online quantitative angiography, intravascular ultrasound (IVUS), flow and pressure wires, and equipment for rotational or directional atherectomy will be found in many centres.

\section{Postprocedural care}

After completion of the procedure, the PCI patient is usually transferred from the cardiac catheterisation laboratory to a recovery area and then on to a general cardiology ward or in some cases to a high care facility. There is a trend towards a shorter inpatient stay and limited but increasing numbers of patients are now being treated on a day case basis. In whatever area the patient is managed, the ward staff should be familiar with the care of the PCI patient, including observation of the point of vascular access (including the care of sealing devices) and haemodynamic and ECG monitoring, together with fluid resuscitation for treatment of vasovagal episodes. There must be close supervision and observation for other recognised complications with ready access to echocardiography facilities for the diagnosis of cardiac tamponade, as well as rapid access to experienced medical assistance. Formal written local guidelines must be developed for the postprocedural management of this group of patients.

Before discharge from hospital, the PCI patient should be given written instructions relating to possible late vascular and other complications, instructions on any changes in medication, advice on driving or other restrictions, and arrangements for return to work and clinic follow up. Many centres now routinely arrange formal cardiac rehabilitation for the post-PCI patient.

\section{Support staff}

A dedicated multidisciplinary team comprising catheterisation laboratory and recovery nurses, radiographers, and technicians should be aware of the potential complications of the procedure, be well versed in all aspects of resuscitation, and be able to cross cover each other should the need arise. The majority of the members of the catheterisation laboratory staff should be trained and competent in advanced life support. They should be encouraged to attend local morbidity and mortality meetings, as well as educational courses and conferences in interventional cardiology.

In a UK environment in which there is a shortage of many of the necessary members of a multidisciplinary team, multiskilling should be encouraged. To this end the introduction of guidelines and protocols for the identification, appointment, and training of generic catheterisation laboratory personnel is to be encouraged, as this approach is likely to allow the expansion of the national PCI service when trained personnel are in short supply.

\section{MONITORING STANDARDS Audit and CCAD}

All centres should collect data on the intervention treatments they provide to their patients. To determine whether the standards of care are acceptable, it is necessary to compare results with some form of benchmark. This can be derived from current research literature but, since treatment strategies change with time, it is probably more appropriate to compare an individual centre's (or operator's) results with those collected by a peer group.

BCIS has advocated this approach for some years and the BCIS audit process has evolved over time. Previously, all centres were asked to provide data on the number and type of cardiac interventional procedures performed as well as the in-hospital clinical results of these treatments. It became clear that many centres lacked the infrastructure to collect accurate data. BCIS has made recommendations previously on the requirements for a successful audit programme ${ }^{15}$ :

- BCIS provides a clinical dataset (see appendix 1 on the Heart website-www.heartjnl.com/supplemental) to allow a national comparison of results of interventional techniques and encourage the uptake of the audit process. It will provide consistent definitions of variables used in the dataset. The Society will work with the DoH to provide a central database (see below) and will aim at developing a means of risk stratified data analysis and providing an analysis of an individual department's (or operator's) case mix.

- A trust or hospital should provide the appropriate audit and information technology infrastructure to a cardiology department to allow clinicians to collect accurate data and to ensure that it is analysed and made available to commissioning groups and other interested parties. This includes the appropriate personnel to ensure accurate data collection and validation (for example, audit nurses and audit clerks). It should have a system of clinical governance to oversee the results of the treatments provided.

- A cardiology department should appoint a key clinician to lead on an audit process for interventional cardiology, ensure that there is an appropriate method to collect and analyse data, and ensure that the Trust has provided appropriate support staff to make this process work. Departmental data collection systems must be compatible with the national dataset. Compatibility requires not only accurate data collection but also a means of secure transmission of the data to the national database. Cardiology departments should ensure that all interventional cardiologists conform to the process and make their clinical results available as part of the Trust's clinical governance process. Each department should have a policy for taking blood for cardiac enzyme evaluation 6-24 hours after a procedure (even for patients treated as day patients). At present, BCIS requires measurement of creatine kinase and creatine kinase $\mathrm{MB}$, the latter being required for all patients with a raised creatine kinase. Many centres are also collecting troponin concentrations before and after intervention. All centres should report on outcome related to the inpatient stay during the patient's admission for angioplasty; catheterisation laboratory outcome data alone are not sufficient.

- Every interventional cardiologist should conform to the department's audit process, collect data on his or her patients, and share the results of the treatment with the Trust's clinical governance programme.

These recommendations should apply to all centres performing interventional cardiology techniques, including NHS and private centres. Each centre should have an appropriate computer based database. BCIS has developed a database that is compatible with the BCIS/CCAD data requirements (see appendix 2 on the Heart websitewww.heartjnl.com/supplemental). The dataset collected on 
each patient should contain at least those data variables recommended by the BCIS Audit Sub-Group. This is available in appendix 1 (see the Heart website-www.heartjnl.com/ supplemental) and on the website of CCAD (www.ccad.org. uk). The dataset will change over time and BCIS will feed back to all centres whenever a change is required. At present, this exercise relates only to coronary interventions, but BCIS will develop a similar process for other interventions (such as mitral valvoplasty or atrial septal defect closure) in due course. In 2004 BCIS formalised the governance process in relation to CCAD, forming a tripartite PCI oversight group comprising BCIS, the Healthcare Commission, and the DoH, with the aims of safeguarding confidentiality, providing the Healthcare Commission with information and analysis, and being responsible for modifications of the dataset when necessary.

In 1998/9, coronary interventions were the subject of an evaluation by NCEPOD (www.ncepod.org.uk). ${ }^{7}$ This was a single rather than recurring exercise but may be repeated in future. If so, all interventional cardiologists will be expected to participate in the process.

New technologies should be introduced in an open and transparent manner. Certain technologies (for example, a minor design variation in an already established stent or a new stent with very similar properties to those of others on the market) will not need to go through an internal regulatory process. However, the new device should be approved by the Medicines and Healthcare products Regulatory Agency (www.mhra.gov.uk) and conform to the manufacturing quality requirements of the European Union (that is, it should have a CE (Conformité Européenne) mark). These requirements are necessary for any technology used but whenever a new technology with a fundamental difference in design or function is introduced (for example, the introduction of brachytherapy or drug eluting stents) an internal regulatory process is strongly recommended. In these circumstances, it is recommended that individual operators or departments contact their local clinical governance committee and local ethics committee and that they provide some means of informing the patients to be treated of the change in practice as well as recording the outcomes of patients treated.

In 2002, the government introduced a new system of appraisal for new health technologies. The many agencies that were involved in the process in the past have been brought together under the auspices of NICE (www.nice.org. uk), which has taken over the responsibilities of the Safety and Efficacy Register for New Interventional Procedures (SERNIP). This was formerly a responsibility of the Academy of the Medical Royal Colleges. NICE guidance on interventional procedures is developed by an independent interventional procedures advisory committee made up of professionals working in the NHS and people who are familiar with the issues affecting patients and carers. The committee, which meets monthly, takes advice from specialist advisors nominated by professional bodies with members who are involved with and experienced in the use of interventional procedures. NICE consults publicly on all guidance before it is issued. BCIS has a nominated member on the interventional procedures advisory committee and provides advisors to the assessment process. All interventional centres are expected to take account of the recommendations made by NICE.

\section{New technologies}

As with the development of new drugs, new interventional devices have to undergo a rigorous series of tests before their clinical application. New treatments require evidence of clinical and cost effectiveness. Pending such evidence, new treatments should only be used in the context of a formal clinical trial or independent evaluation. This will help ensure advances are introduced to the NHS as speedily as possible without patients being exposed to undue risk. After favourable pilot studies a new device should be tested on a wider cohort of patients by selected clinicians committed to accurate data collection.

Ideally, the device should be tested through the rigors of a randomised study; single or double blinding is often not possible in this situation. Before clinicians participate in a randomised trial, they should be experienced with the use and the optimal technique of the device. This requires a planned training programme. Some devices are aimed at specific problems that might not occur commonly and will require multicentre collaboration; randomised trials are difficult under these circumstances, and sometimes the effort and expense involved are prohibitive. Alternative sources of evidence include prospective observational registry data, and even isolated case reports can have an impact on the selection of treatment for specific problems.

Once a device is approved, use will depend on a number of issues including the frequency of the clinical problem and the cost effectiveness in relation to existing technologies; given the present nature of funding of treatments, cost effectiveness must also be documented.

All new developments in the field of PCI have been designed to do one or more of three things: enable treatment of a lesion at lower risk than conventional treatment; reduce the rate of restenosis; and allow more complex cases to be treated by catheter based technology.

The uptake of most devices is led by the demand for a solution to a clinical problem, and the development of new devices has generally arisen out of collaboration between clinicians and industry. Scientific literature, educational programmes, and marketing all lead to the widespread uptake of the device. Purchasers of health care have to be persuaded to invest extra funds for the treatment (or to reorganise overall funding). The clinical community (whether individually or through societies, research groups, or royal colleges) has to be transparent with patients and society as a whole, demonstrating that they are delivering a high level of care. Lastly, government agencies, acting on behalf of society, should be more involved in demonstrating that these steps have been taken.

Although many clinicians are concerned that too much of a bureaucratic approach will slow developments, limit accessibility to treatments, and ration treatment, it behoves interventionists to develop a close working relationship with these agencies, to enable best care to be delivered at an acceptable cost to our patients. The Council of the BCIS holds the view that the Society should take a clear lead in working together with such agencies in the UK and has already taken steps to develop such working relationships. Some of these agencies are described below.

\section{New interventional devices: non-clinical interested parties The royal colleges}

The various royal colleges, including the Royal College of Physicians (www.rcplondon.ac.uk), have together developed an Academy of Medical Royal Colleges (www.aomrc.org.uk) and this body used to have responsibility for the SERNIP, created in 1996. This acted as an advisory body to the NHS. However, the responsibility for the function of this registry was transferred to NICE from April 2002 (see below).

\section{Department of Health}

The DoH (www.dh.gov.uk) is a vast governmental body with a budget of $£ 54$ billion (2003/4). Within the organisation are five bodies that relate to interventional devices: 
- Medicines and Healthcare products Regulatory Agency. From 1 April 2003, the MHRA replaced the Medical Devices Agency and the Medicines Control Agency. The MHRA is an executive agency of the DoH with trading fund status. The Agency is committed to safeguarding public health by ensuring that medicines, health care products, and medical equipment meet appropriate standards of safety, quality, performance, and effectiveness, and that they are used safely.

- Radiation Protection Division (Health Protection Agency) The Health Protection Agency was established as a special health authority (SpHA) in 2003. Its role is to provide an integrated approach to protecting UK public health through the provision of support and advice to the NHS, local authorities, emergency services, other Arms Length Bodies, the Department of Health and the Devolved Administrations. On 1 April 2005, the agency was established as a non-departmental public body, replacing the HPA SpHA and the National Radiological Protection Board (NRPB) and with radiation protection as part of health protection incorporated in its remit (www.hpa.org.uk/radiation).

- NHS Research and Development Directorate. Within the NHS Research and Development Directorate is the Standing Group for Health Technology Assessment (an advisory group), which is part of the Health Technology Assessment Programme. The group that is responsible for coordinating the health technology assessment programme is the National Coordinating Centre for Health Technology Assessment (www.ncchta.org) (part of the Wessex Institute for Health Research and Development at the University of Southampton). The NHS research and development directorate is also responsible for NHS research funding. The NHS funding for research and development is separated into two streams: one is the NHS support for science (part of which was previously referred to as Culyer funding), which is directed at the additional costs to hospitals for participation in research; the other is the NHS priorities and needs research and development funding that underpins modernisation and quality improvement in the services the NHS provides. The NHS research and development levy incorporates three streams of work: health technology assessment; service delivery and organisation; and new and emerging applications of technology (www.neatprogramme.org.uk). Application for funding for research can be made to the regional grantgiving bodies. The new and emerging applications of technology programme provides funding for the application of recent advances in knowledge and technology to the development of new products and interventions for improved health and social care and for disease prevention and treatment. There are other sources of research funding, such as the Medical Research Council (www.mrc.ac.uk). The Medical Research Council comes under the jurisdiction of the Office of Science and Technology (now part of the Department of Trade and Industry) but is linked to the DoH. Otherwise, research funding comes from charitable bodies (such as the British Heart Foundation, www.bhf.org.uk).

- National Specialist Commissioning Advisory Group (NSCAG) (www.advisorybodies.doh.gov.uk/NSCAG/). This is another advisory group to the DoH that recommends which highly specialised NHS services should be commissioned centrally-for example, pulmonary hypertension, liver transplantation, chorioncarcinoma services, and ocular oncology. Such services are designated and as such can be provided only from recognised units, which are normally funded centrally. This is not always the case, however, and in some circumstances local NHS commissioners provide funding (for example, for cardiac transplantation or pulmonary hypertension services). Non-designated providers should not treat patients requiring such highly specialised services. NSCAG now works with the regional specialist commissioning groups to decide which services should be provided regionally or nationally. NSCAG can also fund the service costs of new technologies that are undergoing formal evaluation (for example, adult extracorporeal membrane oxygenation) if, after successful evaluation, the resulting service is likely to be national. NSCAG would be unlikely to consider paying the service costs during the evaluation of something like brachytherapy, as any resulting service would be likely to be delivered at regional level at least.

- National Institute for Health and Clinical Excellence (NICE) (www.nice.org.uk). This is also part of the DoH. It was set up as a special health authority for England and Wales, and its role is to provide patients, health professionals, and the public with authoritative guidance on "best practice". Guidance covers both individual health technologies and clinical management of specific conditions. In the field of PCI, NICE has published appraisals on the use of glycoprotein IIb/IIIa receptor blockers ${ }^{16}$ and intracoronary stents ${ }^{617}$

\section{British Cardiac Society}

The BCS (www.bcs.com) is a charitable body that was established in 1922. The majority of the BCS membership are UK cardiologists and cardiac surgeons but the membership also includes other doctors and health care professionals. The Society is involved in education, the setting of clinical standards, and research into heart and circulatory diseases. The BCIS is one of the affiliated groups of the BCS.

\section{Organisation within $\mathrm{BCIS}$}

BCIS (www.bcis.org.uk) Council includes a member of the MHRA. In addition, the President of the Society has close links with the National Director for Heart Disease, NHS Executive, who with the Heart Team is responsible for developing government policy on cardiac services. Links with the DoH have also been strengthened by the BCIS's participation in the CCAD Project (www.ccad.org.uk). The BCIS audit programme and in future its investment in CCAD, will allow the tracking of new devices and the clinical results obtained. BCIS has also created a subgroup (the Data Monitoring Committee), one responsibility of which will be to inspect data from the audit programme and report back to the Society. The President of BCIS sits on the Council of the BCS, thereby providing feedback to the entire cardiology community in the UK. Although Scotland has its own health programme cardiologists working there are neither excluded from (nor immune to) any of these processes.

\section{PEER REVIEW}

Peer review forms a critical component of the process of assessment of continued competence. The purpose of peer review is to provide an expert view of a individual's ability to meet professionally acceptable standards and thus help ensure an acceptable level of continued professional competence. Such review may necessarily identify individuals who do not conform to acceptable standards and who may therefore be required to undergo retraining or be suspended. If the outcome of a peer review can put at risk the ability of an individual to continue to practice, then such a review has to be rigorous. It would need to be supported by accurate statistics and involve comparison with performance standards accepted by the speciality as a whole. Such detailed performance standards for individuals do not yet exist for 
interventional cardiology. Previous BCIS/BCS guidelines for the practice of coronary angioplasty do not identify performance standards for individuals in terms of their knowledge, dexterity, judgement, and outcomes. ${ }^{12}$ Where there have been attempts at specifying standards of knowledge and skills such as the in the ACC Clinical Competence Statement, these attempts remain very generalised. ${ }^{12}$ While listing standards such as "... an operator would be expected to be up to date with adjunctive therapies", for example, how this standard might be assessed or tested is not mentioned.

Other attempts at identifying performance standards in this difficult area tend to identify one or two "good" centres with published complication rates and suggest that this establishes a standard. All other individuals can then be judged against these standards. This amounts to saying that the view of peers is the most appropriate assessment. All quality assurance programmes rely ultimately on peer review, often in the form of an expert panel, to set the standards and the limits of acceptability and for unbiased peer review to take place.

If there were a proper set of standards for individual coronary interventional operators then a peer review of individuals may be possible. However, such a review would involve two or three cardiologists making a full assessment of one other cardiologist; such a full assessment would take at least one day to complete, not allowing for the time for the preparation of documentation, case notes, angiograms, etc, and the generation of a report afterwards. If each operator were to be fully reviewed once every three years by two interventionists then 210 interventionist days/year would be spent, an equivalent almost to one whole time interventionist. It is our view that an effective general system for individual operator peer review is not possible, feasible, or practical and would probably not be good value for money.

Instead, detailed individual operator review could take place only of those operators giving cause for concern-for example, in the case of complication rates that may stand out after analysis of the routine audit data, information from "whistle blowers", or concerns derived from the unit peer review outlined below. Even in such cases a great deal of consideration would have to be given to the method of individual review and we consider that it is inappropriate that any attempt should be made to include it in this paper.

We consider a unit peer review appropriate. The unit peer review should be a review of the interventional cardiology unit as a whole with the express target of being able to pass it as a unit performing angioplasty to an acceptable standard. The result of unit peer review can therefore only be (a) that the unit is performing angioplasty to an acceptable standard; (b) that the unit is performing angioplasty to an acceptable standard but that there are areas that show cause for concern; or (c) that the unit is not performing angioplasty to an acceptable standard.

At the request of the BCS, BCIS has initiated a pilot scheme for unit peer review. Our experience to date indicates that unit peer review takes one day to complete and involves two visiting interventionists from an outside strategic health authority. In the pilot scheme, units have requested unit peer review; in the future all units undertaking PCI will undergo unit peer review on a regular three to five year cycle, which will be arranged under the auspices of the Professional Standards and Peer Review Committee of the BCS. As such the assessment of PCI will be integrated into a visit that will encompass unit peer review of all the cardiac related activities of the unit.

For PCI, the unit peer review itself compares the unit with the guideline in the following areas:

- Equipment. A review and documentation of the equipment available for the generation of the angiographic images and the safe support and monitoring of vital functions during procedures. A review of the available range of interventional tools and adjunctive pharmacology.

- Operators. A review of operators' past and current experience as first and second operator and comparison with guideline recommendations.

- Personnel. A review of the numbers and experience of the nurses, technicians, and radiographers.

- Pre-, peri-, and postprocedural care. A review of the overall care of a patient undergoing an angioplasty by attending at least one patient from ward to recovery area.

- Evidence of audit and case review. An assessment of the performance of a unit by discussion with the interventionists involved, which can provide a biased viewpoint. The process of "triangulation", the gathering of views from those other than the operator involved, has proved vital in other areas of peer review and we have found it very useful in the unit peer review process. Confidential discussion with a senior technician, nurse, or radiographer may throw a different light on some of the unit's practice that may not be reflected in that particular way by discussion with the interventionists themselves. Discussion with the specialist registrar in intervention may also be illuminating. It would not be appropriate for the unit peer review to consider training issues but it would be appropriate for the unit peer review to assess the degree of supervision for trainee operators with the quality of the PCI procedure in mind.

\section{TRAINING}

Training only in the technical aspects of performing procedures is inadequate given the complexity of the procedures. A training programme must ensure that its trainees acquire a sound knowledge base of the basic principles that underpin the practice of interventional cardiology. It is recommended that training programmes have a core curriculum that covers these important basic principles. The important topics that need to be covered are as follows:

- Anatomy and physiology pertaining to the cardiovascular system. In particular the trainee needs to understand coronary anatomy, its variations, and congenital abnormalities. The trainees need to understand cardiac haemodynamic functions and coronary physiology.

- Pathophysiology of cardiovascular disease.

- Pharmacology principles to provide an understanding of cardiovascular drugs. Trainees need to understand the indications for and complications of contrast agents and drugs commonly used for invasive procedures. Principles of haemostasis including indications for and complications of vascular closure devices should be covered.

- Radiology imaging and radiation safety. This should include design and operation of $x$ ray cine angiographic units, basic radiation physics, radiation quality assurance, physiology of radiographic contrast media, digital imaging and archiving, factors influencing image quality, and an understanding of the biological risks from radiation exposure so as to minimise radiation exposure to the patient and catheterisation laboratory staff.

- Knowledge of quantitative coronary angiogram analysis.

- The design and performance of interventional devices.

- Clinical management strategies to include case selection, performance of the procedures, and subsequent management of the patient before discharge and beyond. A clear 
understanding of the indications, limitations, and complications of the procedures must be acquired.

\section{Training in cardiac catheterisation}

Before undertaking training in interventional cardiology the trainee must achieve competence in general cardiology and in diagnostic cardiac catheterisation, which should usually be possible during the first four years of the specialist registrar clinical training. The trainee should have performed a minimum of 500 diagnostic cardiac catheterisation procedures in which the trainee was a primary operator. These should include left heart catheterisation and coronary arteriography, as well as venous bypass and internal mammary graft studies.

In the first four years of the specialist registrar training period the trainee is expected to have assisted at 25 PCI procedures, but formal training in coronary interventional procedures does not start until the last two years. Ideally, training should be focused predominantly on patients undergoing diagnostic and interventional cardiology procedures during these last two years.

\section{Selection}

The process of selection of an interventional trainee differs in different institutions with no agreed mechanism nationally. Competitive interviews are held in some whereas no structured or consistent process appears to be in place in others. It is recommended that training institutions have in place a method of formal assessment and selection for the training places that can withstand fair scrutiny. Ideally the selection should be made during year four or five of the specialist registrar training when the trainee will have been trained in left and right heart cardiac catheterisation by both the femoral and radial approach, and the trainee's ability can be assessed objectively. If it is considered that training would be appropriate for an individual but circumstances are such that the training cannot be provided locally, an interdeanery transfer should be considered.

\section{Core procedures}

A core experience in the following interventional techniques should be provided by the training programme:

- Conventional balloon angioplasty

- Coronary artery stenting (including drug eluting stents)

- PCI in the setting of ACS including primary intervention for ST elevation MI and rescue angioplasty

- Pericardial aspiration

- Intra-aortic balloon counterpulsation and other techniques of mechanical circulatory support.

Experience in other techniques would depend on the expertise and practice of the institution experience. These include training in the following:

- Atherectomy (directional and rotational)

- IVUS

- Coronary flow measurements/pressure wire measurements

- Use of protection devices, filter wires, etc

- Laser based procedures

- Intracoronary brachytherapy

- Embolisation devices (for example, coils)

- Intravascular foreign body retrieval

- Balloon valvoplasty

- Transcatheter closure of congenital/acquired defects.
Local arrangements with neighbouring centres should be encouraged for trainees to be able to train in techniques not available at the host institution. Experience in at least two arterial access routes should be encouraged (for example, femoral, radial, and brachial). The trainees should have experience in treating the full morphological range of coronary lesions.

\section{Procedural numbers}

The main change in the cardiovascular medicine curriculum being proposed by the Joint Committee on Higher Medical Training is the method of assessment of practical procedures. "Numbers of procedures" are no longer sufficient and it is proposed that practical skills should in future be assessed on a competency basis. A log book is still to be kept for practical procedures, and observations by the educational supervisor and by a consultant other than the educational supervisor of the technical skills will be part of the assessment methods.

The shift towards competency based training with less dependence on numbers of procedure is a welcome change in emphasis but is at odds with the emphasis on numbers in terms of recommendations for assessment of proficiency for individual operators and institutions. It is the BCIS view that number of procedures does still form an important part of training and should remain an integral part of the assessment of a trainee in conjunction with other methods of assessment. Defining the minimum number of PCI procedures that constitutes an acceptable training in angioplasty, however, is difficult because individuals learn at different rates and case selection and available facilities will differ between centres. It is our recommendation that trainees perform a minimum of 200 procedures over the last two years of the six year training programme, with a minimum of 125 procedures as first operator. At least 150 of these procedures should have been undertaken at the tertiary or surgical centre. The training should have the following components:

- The trainee must be fully involved in the preprocedural evaluation of the patient to assess the appropriateness and to plan a procedure strategy in terms of selection and use of basic equipment such as guiding catheters, wires, balloons, and stents. Patient selection should include discussion of potential risks, benefits, and alternative treatment options. This is particularly important in special clinical subgroups such as patients with renal failure, diabetes, multivessel disease, or impaired left ventricular function.

- It is not uncommon for more than one operator to be involved in PCI procedures and it can sometimes be difficult to define clearly the principle operator. However, for the purpose of training it should be left to the trainer to determine when a trainee has been the principle, as opposed to assistant (second), operator. The trainee must personally perform the procedures under the direct supervision of a recognised trainer. The trainer who takes overall responsibility for the patient must be immediately available in the catheterisation laboratory to supervise the trainee.

- The trainee should be directly involved in the reporting of the procedure and be actively involved in postinterventional patient management. This includes managing vascular access site haematomas, bleeding, and closure devices, as well as managing anticoagulation issues, assessing other possible complications, and discharge planning of the patient to include follow up care.

- Trainees should be exposed to a comprehensive range of patient mix and these should include patients with stable angina and ACS such as unstable angina, acute MI, and cardiogenic shock. All trainees should be able to acquire 
significant experience in the management of patients who require circulatory support, particularly with intra-aortic balloon counterpulsation.

- Trainees must be familiar with the BCIS/CCAD audit requirements for PCI and be aware of and participate in data collection and validation.

\section{Education}

BCIS recommends that an interventional training programme should hold a regular interventional meeting. This should address the core curriculum subject matter and should provide an opportunity to review both the diagnostic and interventional cases with respect to patient selection, the performance of the procedure, clinical outcome, and any complications. Ideally a joint cardiology and cardiac surgery clinical meeting should also take place to allow discussion between the two specialities, which is an integral part of any decision making.

Participation in clinical research by the trainees should be a core requirement for the programme. Trainees should be encouraged to initiate individual research and participate in trials in which the institution is taking part. Trainees should be active participants in data analysis and presentations and be encouraged to undertake clinical audit and follow up of patients. Trainees should spend at least four days each year attending appropriate educational meetings, which in the case of an advanced trainee in PCI would be at interventional meetings-for example, BCIS Advanced Angioplasty meeting, Euro-PCR Meeting (Paris), or Transcatheter Cardiovascular Therapeutics Meeting (Washington).

\section{Trainers}

Each institution with an interventional training programme should have at least two experienced clinical interventional consultant cardiologists who have performed a minimum of 500 procedures in their career and whose procedure volume now is a minimum of 125 procedures personally a year. Not all the trainers need to have expertise with all the interventional techniques and devices but there should be a diverse mix of trainers who provide expertise in each of the core techniques as specified earlier. Each centre should designate a programme director, who is responsible for the interventional trainees, the content of the training programme, and ensuring trainee selection, appraisal, and assessment. The programme director should have a career experience of a minimum of 1000 coronary interventional procedures. An interventional training centre should perform a minimum of 400 PCI procedures a year to allow a trainee to participate in the management of the full spectrum of cardiac patients. We also recommend that the number of trainees accepted into a training programme should reflect the institutional volume and the number of senior trainers available. Generally a PCI programme should be an integral component of a comprehensive service and ideally should have on-site capabilities including a coronary care unit, cardiac surgery, cardiac intensive care, echocardiography, and nuclear cardiology. It is recommended that training programmes be based in centres with on-site cardiac surgical facilities. However, where large volume PCI programmes have been established without on-site cardiac surgery, trainees may be placed in such institutions provided institutional volume and trainer requirements are met and where this training is part of a rotation in which the trainee is exposed to training in a surgical centre as well. It is strongly recommended that when trainees are placed in centres without on-site cardiac surgery careful arrangements be made for the trainees to interact with neighbouring on-site surgical centre interventional trainers and trainees together with the cardiac surgeons.

\section{Trainee evaluation}

Responsibility for trainee evaluation should reside with the programme director in collaboration with the other programme trainers. The trainee is expected to maintain a log book of all catheterisation laboratory procedures throughout training. A system of rigorous compilation of trainee experience and assessment of the trainee's knowledge in technical skill should be put in place with a system of feedback. The assessment process needs to be diverse and should also incorporate the new recommended methods such as annual reflective observations from other team members, multiple choice structured question assessments, and a portfolio of educational achievements. The programme director should be responsible for confirming that trainees have completed their interventional training satisfactorily as required by the core training requirements.

\section{SURGICAL ISSUES Surgical cover}

The need for surgical cover merits continued evaluation. Some operators would maintain that, since the introduction of intracoronary stents, glycoprotein IIb/IIIa receptor blockers, and allied technology, the role for emergency surgery has diminished to such an extent that it may no longer be necessary. The UK national data indicate that the need for emergency CABG has fallen since stenting has become routine; in 1991, emergency CABG was required by 258 patients $(2.6 \%)$, whereas in 2003 , only 154 patients $(0.29 \%)$ required to have emergency CABG (fig 2); this is a fall in absolute numbers of around $40 \%$. The contemporary ACC/ AHA guidelines for PCI (2001) quote a similar figure of $0.4 \%$ for emergency CABG. ${ }^{12}$ In the NCEPOD report (1998/9), $0.87 \%$ of patients ( 141 of 16269 ) died after PCI, but in this subgroup only four patients were emergently transferred from the catheterisation laboratory to surgery after failed PCI (four of $141(2.8 \%)$ ), with an additional two patients requiring $C A B G$ within 24 hours. More commonly patients referred for emergency surgery at the time of PCI survive. The emergency surgery rate after PCI taken from the BCIS report of the same time frame quotes a figure of $0.7 \%$ of 16269 patients undergoing emergency surgery at the time of PCI. This equates to 114 patients. Outcome data are not available for the surgical results of this cohort but assuming that those who go to theatre were at risk without surgery then some 114 patients potentially survived who otherwise may have either died or suffered significant morbidity at the time of PCI.

Despite the decline in the referral for emergency CABG a significant number of patients will survive due to the availability of emergency surgery, when they may otherwise have died after failed PCI, and BCIS feels that adequate provision for cardiac surgery is still a prerequisite to safe PCI.

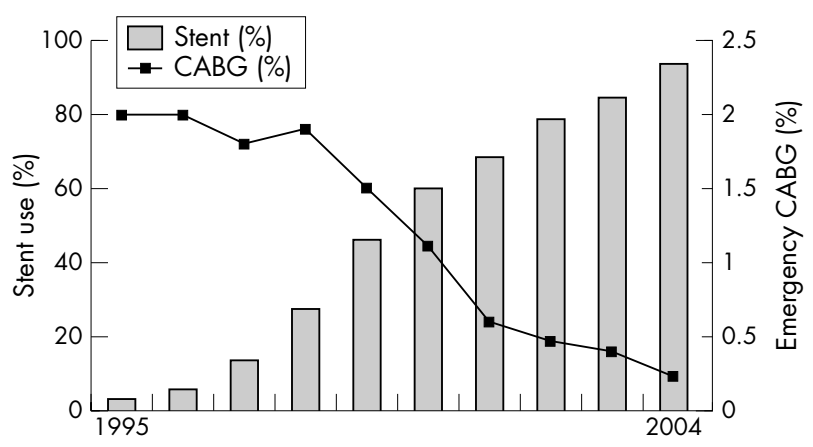

Figure 2 Relation between stent use and the requirement for emergency CABG. Source: British Cardiovascular Intervention Society. 
In some specific patient subsets undergoing PCI emergency CABG is less likely to be of benefit; these include primary PCI for acute MI, rescue PCI after failed thrombolysis, salvage PCI for cardiogenic shock, and possibly failed PCI in a patient who has undergone previous CABG and is deemed by prior clinical agreement to be unsuitable for further surgical revascularisation. As a general principle, the patient who does not require surgical cover should be identified and the overall treatment plan agreed with the patient and surgeon before embarking on PCI.

In discussing the provision of surgical cover it is necessary to define the level of surgical cover, the timeliness of cover, communication between members of the multidisciplinary team, and the haemodynamic support of the patient awaiting surgical revascularisation.

Timing is important, as there is a clear relation between myocardial salvage and the time to establishing cardiopulmonary bypass. Much of the delay between the onset of ischaemia when a major coronary artery is occluded relates to the attempts of the interventional cardiologist to reopen and reconstruct the artery, rather than the subsequent delay in transferring the patient from the catheterisation laboratory to the operating room. In the stent era, it is likely that the cardiologist will persevere for longer, thereby delaying the surgical option, with the potential of increasing the ischaemia and worsening the surgical outcome; hence, referrals to surgery are declining. It can be seen that the decision and timing of surgical referral are completely dependent on the judgement of the interventional cardiologist: as such, this area should be regarded as an extremely important aspect of training in PCI.

In the contemporary NHS, resource limitations are such that the availability of a fully equipped and staffed operating room (true "standby") is not feasible, except in exceptional circumstances; nor could it be justified with such an infrequent need. In only a small minority of cases will a particular patient have been discussed with a surgeon before intervention, although it is recommended that specific patients should be discussed when an interventional approach may be contentious or when a decision needs to be made on whether surgery has any role at all if PCI fails. In certain groups of patients (for example, those with unprotected left main stem (LMS)) a heightened level of standby may be appropriate with the PCI procedure timed in relation to the availability of an empty operating room.

As in previous guidelines, BCIS recommends that all centres should be in a position to establish cardiopulmonary bypass within 90 minutes of the referral having being made to the cardiac surgical service. There is no clear evidence that centres with on-site surgery will necessarily be in a position to have the patient on bypass any quicker than the centre without on-site surgery; sometimes the converse may be true. Whether the surgical team is on or off site, it is the responsibility of the interventional cardiologist to communicate with a recognised contact person to determine the availability of the appropriate staff (surgeon, anaesthetist, perfusionist, or scrub nurse) as well as the availability of an operating room and an intensive care bed. This approach will allow for staff absence, sickness, bed closures, methicillin resistant Staphylococcus aureus outbreaks, etc. The surgical team should be aware of the scheduling of PCI procedures, both within the working day and out of hours. Methods of communication must be formalised and written local protocols agreed between the various parties: these should be regularly updated to reflect changing practice.

Centres undertaking PCI must be experienced in all aspects of managing the haemodynamically unstable patient including the use of echocardiography, inotropic support, invasive monitoring including Swan-Ganz catheterisation, temporary pacing, oximetry, intra-aortic balloon counterpulsation, and assisted ventilation. The NCEPOD report emphasised the underuse of intra-aortic balloon counterpulsation in patients with cardiogenic shock. ${ }^{7}$ High care and intensive care facilities with fully trained nursing, technical, and radiographic staff should also be available.

\section{Off-site surgery}

In the UK, increasing numbers of patients undergoing PCI are treated in centres without on-site surgery: in 2004, 20 centres $(26 \%)$ did not have on-site surgical facilities accounting for $15 \%$ of all cases (9390 patients). In the NCEPOD report, in only $5 \%$ of deaths (six of 121 ) was surgery undertaken at a site remote from the index hospital. Nevertheless the current ACC/AHA guidelines do not support elective PCI being undertaken in centres without on-site surgery: the report concludes that "...the Committee therefore continues to support the recommendation that elective PCI should not be performed in facilities without on-site cardiac surgery". As with many dynamic areas in interventional cardiology, the North American recommendations may be subject to revision as clinical data and experience increase. ${ }^{12}$ European practice meantime has continued to evolve with off-site cover being increasingly widespread. BCIS supports the concept of PCI being performed in centres without on-site surgery provided these centres can fulfil all the operator and institutional standards outlined in this document. It is likely that increasing numbers of centres without on-site surgery will open over the next few years that will significantly increase the proportion of patients undergoing PCI without on-site surgical availability. In some groups of emergency patients treated with PCI in district hospitals, surgical cover will not be required (see above), but for elective patients a robust arrangement needs to be in place between the district general hospital or non-surgical centre and the local surgical centre.

All the previously described criteria need to be met by the non-surgical centre. The relationship between the cardiologists in the non-surgical centres and the local cardiac surgeons is fundamental to a safe and successful outcome. The transfer of a patient between one centre and another must be considered in the greatest detail and should be agreed in writing between the local hospital, the ambulance service, and the surgical centre. Arrangements for patient transfer will vary from one centre to another and may include a dedicated ambulance, helicopter, etc, depending on local access issues. Local networks will need to address local solutions with all parties involved. Reliance on the regular ambulance service is unlikely to be satisfactory because of the potential unavailability of an ambulance and therefore the unpredictability of the transfer time. Other issues that must be addressed include the availability and training of the staff to accompany the patient and the necessary equipment that will include a transportable intra-aortic balloon counterpulsation. Particular thought should be given to balloon pump purchase, as not all units are transferable by ambulance. BCIS recommends that the system be tried and tested to check that the 90 minute guideline can be met.

To ensure consistency and patient safety, the guidelines for off-site surgical cover should be exactly the same as those for on-site cover. The success of the cover arrangements will depend on precise communication between the two centres. It should be made clear to the patient as part of the consent process that surgical cover will be provided by another centre distant to the host unit.

\section{Surgical relationships}

As important as surgical cover is the relationship between the interventional cardiologist and the cardiac surgeon. An 
individual patient should be offered the appropriate revascularisation procedure for his or her condition, be it PCI or CABG. Criteria for referral are changing rapidly due to developments in both technology and skills; operators (either cardiologists or surgeons) practising in isolation are likely to become out of touch with new techniques or new data that will affect clinical decision making. Some advances in interventional techniques (for example, drug eluting stents, arterial conduit usage, and less invasive surgery) will have a profound effect on the decision to refer for surgical revascularisation; this was true with the introduction of bare metal stents in 1993.

In a set of guidelines it is not possible to define precisely which patient should be treated with which technology, as this will depend on many factors including coronary anatomy, co-morbidity, the skill of the operator, patient choice, waiting lists, and even budgetary decisions in a particular institution. Consensus as to the applicability of technology for a particular patient can be achieved as a result of discussions between interventional cardiologists and their surgical colleagues. Practising in isolation is more likely to be a problem in non-surgical centres and for this reason regular joint meetings between centres working within the clinical network should be encouraged. These meetings should include discussions on clinical decision making, choice of equipment, and an audit of morbidity and mortality.

\section{INFORMED CONSENT}

Since the last set of guidelines was published, two important documents have been published relating to consent. The General Medical Council in the publication Good medical practice (3rd edition, May 2001) ${ }^{18}$ states that "...you must respect the right of patients to be fully involved in decisions about their care. Wherever possible, you must be satisfied, before you provide treatment or investigate a patient's condition, that the patient has understood what is proposed and why, any significant risks or side effects associated with it, and has given consent." Detailed guidance is provided in the General Medical Council publication "Seeking patients' consent: the ethical considerations".${ }^{19}$ Additional information is provided in the DoH paper published in April 2001, "Reference guide to consent for examination and treatment". ${ }^{20}$

A patient undergoing PCI should expect to be told the treatment options, the risks and benefits of treatment, details of the procedure (including practicalities, nature of discomfort and pain, recovery, rehabilitation, and return to work), the likelihood of success, potential complications (minor and major), expectation in terms of symptom relief, alterations in medication, possibility of recurrence, etc. Ample time should be given for the patient to ask questions, and information relating to the procedure must not be withheld. Patients should be given the appropriate written illustrated material relating to PCI, preferably before hospital admission to give them time to read and understand the information in a relaxed home environment and to be able to discuss the procedure with their family, friends, or general practitioner. Advice, both verbal and written, should be offered in the appropriate language, preferably in the presence of a relative. The BCS (www.bcs.com) provides explanatory leaflets for a variety of procedures, including PCI.

In all cases the likelihood of success and the complication rate should be related to local audit data, preferably physician and case mix sensitive. Complications that should be specifically discussed with the patient include the likelihood of death, acute MI, cerebrovascular event, the requirement for $C A B G$, and complications relating to vascular access (including false femoral aneurysm). The appropriateness of new technology (for example, drug eluting stents) should be discussed, including the limitations of the published evidence and the shortage of long term follow up data. In cases where surgical cover is off site, it is important that the patient understand the arrangements for surgical cover and the potential need for transfer to the surgical centre.

The clinician providing the treatment is responsible for ensuring the patient has given valid consent before treatment begins. The consultant responsible for the patient's care remains ultimately responsible for the quality of the care provided. Consent does not necessarily have to be obtained by the physician undertaking the procedure; the task of seeking consent can be delegated to another health care professional provided that the professional is suitably trained and qualified. In particular, this professional must have sufficient knowledge of the procedure, including the risks involved, and be able to provide any information that the patient may request. Thus, consent may be obtained by an appropriately trained specialist registrar or nurse practitioner but not by an inexperienced junior hospital doctor. Inappropriate delegation may render the consent invalid.

In an emergency presentation, for example of a patient undergoing primary, rescue, or salvage angioplasty, it may be difficult or impossible to obtain truly informed consent from the patient, particularly if the patient has received prior sedation or opiate analgesia or when cerebral perfusion is impaired. In these circumstances it is particularly important where possible to discuss the procedure and inevitably high complication rate in detail with the next of kin or other relatives in the presence of a witness (for example, a senior nurse or a medical colleague). If at all possible, it is preferable that in such cases consent be obtained by the responsible consultant.

In the patient undergoing diagnostic catheterisation query proceeding to PCI (follow on intervention), it is important that the complications related to both the diagnostic coronary arteriogram and the interventional component of the procedure be explained to the patient beforehand: this may be too much information for some patients to comprehend in one sitting. As the complication rate and outcome in PCI improves there is a tendency to understate or not discuss the complications, which makes it more difficult to cope with an unpredicted catastrophic complication when it does occur.

The Human Rights Act 1998 became law in the UK in October 2000, and it is likely to have a major impact on the delivery of contemporary health care. ${ }^{21}$ It should be noted that the standards set for health professionals by their regulatory bodies may at times be higher than the minimum required by law; nevertheless, the legal requirements in medical negligence cases have historically been based on the standards set by the professions.

\section{APPRAISAL AND CONTINUING PROFESSIONAL DEVELOPMENT}

The results of individual operators can be improved by sharing experiences with colleagues, and interventional centres should encourage discussions between operators, both informally and more formally, as part of departmental meetings. Operators should keep abreast of the literature and technological change relating to coronary angioplasty and the rapidly changing field of adjunctive pharmacology. We recommend that trained operators spend a minimum of four days a year attending national and international meetings relevant to their speciality and undertake their own personal audit of their interventional procedures. As a minimum this should consist of keeping a record of all the patients who have received interventional procedures by the operators personally or under their auspices, the patients' preprocedural and procedural details as outlined in the BCIS/CCAD minimum data set, and their in-hospital outcome including 
any postprocedural complications. The departmental audit process should also record any major adverse cardiac events (MACE) that occur over the 12 months after the procedure. Operators should present their data locally to those involved with PCI, such as interventional and non-interventional cardiologists, cardiac surgeons, and radiological, nursing, and technical staff, and the data should be available to commissioners.

Although the process is in its infancy, the appraisal process has to become an integral part of clinical life. Institutional and operator competency will be at the heart of this process, although it has to go hand in hand with continuing professional development. Interventional cardiology procedures are inevitably associated with complications and a mechanism needs to be in place for quality assurance of any programme. The details of the mechanism may vary from institution to institution but some components should remain central to any quality assurance programme. These would be essential considerations for the assessment and maintenance of proficiency in coronary interventional procedures both at individual operator and institutional levels. Clinical proficiency needs to be demonstrated in institutional and individual operator procedure volumes as well as institutional and individual operator complication rates. Training and qualification of the support staff, quality of the laboratory facility, and radiation safety issues need to be taken into account. The demonstration of a quality improvement process with an active database to track clinical and procedure information as well as patient outcomes for individual operators is essential. A mechanism for valid peer review must be established and ongoing at each institution.

\section{NEW CENTRES}

The recognition of a national requirement for a considerable increase in coronary revascularisation procedures is explicit in the NSF for CHD, in which an arbitrary number of at least 750 per million population for each intervention, namely CABG and PCI, provides an initial target level. ${ }^{8}$ Since the publication of the NSF for CHD in 2000, it has become clear that the ratio of PCI to CABG should not be $1: 1$ but rather 2:1 or even greater. The DoH tacitly agreed (2002) that revised figures for revascularisation procedures should be 600 per million population for $\mathrm{CABG}$ and 1200 per million population for PCI. This comes about because percutaneous techniques are increasingly applicable not only to a wider spectrum of coronary anatomy but also to an increasing number of clinical situations, especially within the broad category of the ACS. The anticipated increase in PCI activity is therefore huge. The increase in facilities required to provide this additional activity needs to be considered in line with one of the most important tenets of the NHS plan, equity of access..$^{22}$ Therefore, while enhancing and expanding existing facilities may be appropriate in some settings, in others it may be appropriate to establish new PCI sites. The vast majority of new sites will of necessity be in hospitals without the availability of on-site cardiac surgery; while in the past this would have been considered an inappropriate development it is now acceptable, since PCI has become considerably safer with much less reliance on surgical backup. Four principles underpin the strategic developments in PCI that are set against the background of BCIS developing a peer review system for coronary intervention:

- PCI activity in the UK should increase.

- Development of new PCI sites should be planned and coordinated and not occur on an ad hoc basis.

- All PCI sites should adhere to agreed technical, professional, and practical standards.
- New sites should undergo a peer review visit through BCIS before starting PCI activity. (This has been requested by the National Director for Heart Disease.)

\section{Planning}

The development of a new PCI site should be agreed by the hospital trust with all the relevant stakeholders through a strategic plan worked up through the local cardiac network. Stakeholders should include the local surgical centre(s), the local commissioners of health care including the primary care trusts, the regional or strategic health authority, and the National Director for Heart Disease. It is therefore essential to produce a business plan with which all interested parties agree. It is appreciated that a new PCI site is unlikely to be able to develop overnight from undertaking no PCI to being a fully fledged unit meeting all the guideline criteria. A period of development is obviously required and this should be explicitly reflected in the planning process. Any number of possible permutations may exist that would still satisfy the guidelines and enable high quality PCI to be undertaken. Two examples follow.

\section{Example 1: Allowing explicit time to develop the service}

A district hospital with a catchment population of 400000 and two interventional cardiologists may be seen as an appropriate site for development of PCI. The cardiologists use a mobile catheterisation laboratory for diagnostic work and visit the surgical centre 25 miles away to do PCI. The plan may indicate development to fully fledged PCI unit over a four year period.

\section{Example 2: Utilising available personnel}

A district hospital with a catchment population of 250000 has two interventionally trained cardiologists. There is a dedicated catheterisation laboratory in which they perform diagnostic work but travel to a surgical centre to perform PCI. A second smaller hospital $24 \mathrm{~km}$ away has two cardiologists but only one has training in intervention, which he or she performs in the surgical centre. The first hospital is deemed a suitable place to start PCI because of the local geography and there is already a history of good diagnostic practice, but PCI would be difficult because there are only two cardiologists and the total numbers of procedures would not reach 200 per annum. The cardiologist from the second hospital can have sessional and on-call arrangements with the larger hospital and take patients there, thus enabling PCI to start without delay.

Providing plans such as these, with implementation on a realistic timescale, together with documented agreement of all interested parties and a commitment from commissioners, is most likely to result in successful development of the new PCI site.

\section{Institutional standards}

See section 1 .

\section{Operator and staff standards}

See section 1 .

\section{Monitoring standards}

See section 2 .

Training

See section 4 .

\section{Surgical cover}

See section 5 . 


\section{The $\mathrm{BCIS}$ visit}

A BCIS visit should be requested by the new site by writing to the Honorary Secretary of BCIS. The visit should come when planning is complete, the equipment is installed, and PCI is about to start. The request should come through the Chief Executive of the Trust, who should be made aware that BCIS will expect travel expenses and all reasonable subsistence to be paid by the visited Trust. The BCIS visiting peer review team will comprise two interventional cardiologists from outside the region being visited. A mutually convenient time for the visit will be arranged within eight weeks of the request for a visit. The BCIS team will expect to be able to verify and examine the business plan for the development of PCI, the written agreement of all stakeholders, the written protocol with the surgical centre regarding surgical cover, the catheterisation laboratory facilities, the postprocedural care area and its facilities, the audit arrangements for data collection, compliance with CCAD and meetings with local colleagues, the records of operators' numbers, and a record of continued professional development in PCI (that is, attendance at PCI meetings). To facilitate the visit a form will be sent in reply to the request for a visit (see appendix 3 on the Heart websitewww.heartjnl.com/supplemental). This should be completed and returned as soon as possible. After the visit the BCIS representatives will write a report and submit this to the National Director for Heart Disease, sending a copy to the visited site's Chief Executive and cardiologists.

\section{FUTURE DEVELOPMENTS}

Since the publication of the NSF for CHD in 2000, there has been real progress in the provision of cardiac services. ${ }^{23}$ The DoH now supports the concept of primary PCI for ST segment elevation MI. Following a DoH funded pilot study, it can be anticipated that there will be a significant increase in primary PCI procedures over the next few years. The model of service delivery will vary according to the local geography, the structure of the cardiac network, and the available expertise, personnel, and infrastructure. Overall PCI numbers will increase and it is anticipated that the PCI to CABG ratio will increase from the present 2.5:1 to 3 or $4: 1$ in line with our European colleagues.

Changes in consultant work plans coupled with the demands of the European Working Time Directive will have a major impact on the delivery of cardiac services, offset in part by cardiologists reducing their general medical commitment and a continued increase in the number of appointments of specialist cardiologists. ${ }^{24}$ It has been estimated that 5.1-9.8 intervention consultants per million population are required to undertake 2200-3000 PCI procedures per million population, assuming a working week of 7.5 programmed activities per week. ${ }^{25}$

As it is government policy to reduce NHS waiting times in general and for revascularisation procedures in particular, the division between NHS and private PCI centres will become increasingly blurred as more NHS procedures are undertaken in the private sector as part of a waiting list initiative. It is important therefore that data collection be uniform throughout the service, so that standards are seen to be both maintained and equitable regardless of the point of delivery.

By the time the next set of guidelines is due in 2009, the impact of commissioning by health related groups will have had a profound impact on procedural costs; drug elution is likely to be universal, the use of newer antithrombin agents will be routine, and the promise of effective gene therapy may be have been realised.

\section{CORE EVIDENCE BASE Background}

Health technology association groups such as NICE (www. nice.org.uk) have been established to review the efficacy of existing and new treatments and to appraise technological developments. Cost effectiveness, where effectiveness is judged by the publication of appropriately designed and independently conducted clinical trials, remains central to the review process. Treatments may be considered effective but standard health economic models (such as cost per quality adjusted life year) are employed to indicate whether in the opinion of the NICE committee these are also cost effective. The need to review the evidence base is also driven by the increasing recognition of the need to practice evidence based medicine. Further, within a climate of clinical governance awareness, review of the evidence base for the practice of PCI remains critical.

In 1999 NICE examined the use of coronary stents as the first in a number of cardiovascular exercises, and the report published in May 2000 came out very positively in favour of stenting. It recommended that for patients undergoing PCI stents should be used routinely, that their availability should encourage the use of PCI as opposed to CABG, but that the evidence for their use in vessels $<2.5 \mathrm{~mm}$ diameter was not adequate at that time. There were other caveats such as stent use in unprotected LMS, but stent use in vein grafts was considered acceptable treatment. In 2003 NICE included the data available from trials that tested the benefit of drug eluting stents. The evidence base, they concluded, supported the use of drug eluting stents in all patients included in the trials but was cost effective only in certain subgroups (see below). NICE will revisit intracoronary stents in 2005 .

\section{Evidence base for the practice of $\mathrm{PCl}$}

The evidence available for the use of stents in PCI is generally well known, being based on trial data showing that the use of balloon angioplasty alone is associated with high recurrence rates and that such high rates can be reduced by stenting, which prevents acute recoil and limits late negative remodelling. ${ }^{26-28}$ Review of stent use in the "real world" confirms the reduction in complications such as acute MI and the need for emergency CABG; stenting also appears to reduce in-hospital mortality. ${ }^{29}$ Stent use is now appropriately high $(>85 \%)$ and intervention for clinical restenosis has fallen to $<10 \%{ }^{29}{ }^{30}$ Some outstanding issues remain, however, with published data available to resolve some but not all of these.

\section{The $\mathrm{PCl}$ procedure}

Most operators continue to undertake angioplasty and stenting (PCI) through the femoral route by using catheters of 6 or 7 French diameter or less, although the radial approach has become increasingly popular with the potential advantage of a greater opportunity for same day discharge. The benefit of one approach over the other has not been established in trials, however, with some of the advantages of the femoral approach in terms of success and comfort being countered by shorter bed rest and hospital stay when the radial approach is used..$^{31}$ Recent data suggest that the radiation dose may be higher with a procedure undertaken through the radial approach, although with small numbers (40 coronary arteriograms and 42 coronary interventions), this study may merely reflect a learning curve. ${ }^{32}$ Sandborg et $a l^{32}$ reported that fluoroscopy time and dose-area product were significantly $(\mathrm{p}=0.003)$ higher with the radial access route for coronary angiography $\left(7.5\right.$ minutes, $51 \mathrm{~Gy} \cdot \mathrm{cm}^{2}$, respectively) than with the femoral access route (4.6 minutes, $38 \mathrm{~Gy} \cdot \mathrm{cm}^{2}$ ), as they were for PCI: the fluoroscopy time and dose-area product for radial access were 18.4 minutes and $75 \mathrm{~Gy} \cdot \mathrm{cm}^{2}$ versus 12.5 minutes and $47 \mathrm{~Gy} \cdot \mathrm{cm}^{2}(\mathrm{p}=0.013)$ with femoral access. However, a large retrospective analysis of over 900 patients conducted between 1998 and 2001 suggested that the radial approach can be safely applied as a day case procedure: 811 patients responded and $2.8 \%$ visited 
their doctor or the hospital within 24 hours after discharge because of entry site complications, and 38 patients $(4.7 \%)$ visited within one month. None of the patients had major access site complications or needed to be admitted to the hospital. Within 24 hours after discharge 17 patients $(2 \%)$ reported chest pain and only one $(0.1 \%)$ required a repeat angiogram, which did not show target vessel occlusion. ${ }^{33}$ Clearly, there will always be some procedures (atherectomy, vascular brachytherapy, and perhaps large vessel bifurcation stenting) where the femoral route will be preferred, but the use of the radial approach is likely to increase.

\section{Operator volume}

Some studies have shown that the overall volume of procedures undertaken influences patient outcome. For example, Kimmel et al $^{34}$ reviewing 25000 procedures showed the higher the number of procedures undertaken the lower the incidence of in-hospital coronary bypass (odds ratio for $\geqslant 400 v<400$ PCIs/year 0.6, 95\% confidence interval (CI) 0.4 to 0.8 ). In the setting of higher risk PCI, operator and hospital volume appear to be particularly important. In a retrospective study Magid et $a l^{35}$ showed that the benefits of primary angioplasty for acute MI outweighed those of thrombolysis in high and intermediate volume centres but not in low volume centres (mortality 3.4\% with percutaneous transluminal coronary angioplasty (PTCA) $v 5.4 \%$ with thrombolysis in high volume centres, $\mathrm{p}<0.001$; and $6.2 \% \vee 5.9 \%$, $\mathrm{p}=0.58$, in low volume centres). It is on the basis of such data that the minimum numbers for PCI in the UK have been set. In the era of expanding and devolved angioplasty practice, the introduction of a scoring system similar to that used by cardiac surgeons becomes important with a number of potential benefits, including the cross referral of higher risk patients to more experienced operators, the objective prioritisation of patients on the waiting list, and the ability to formally assess the influence of case mix on complication rates.

\section{Direct stenting versus predilatation}

It has been suggested that direct stenting may have significant advantages over balloon predilatation as a result of less unprotected barotrauma coupled with reduced equipment cost. Several reports and three published randomised trials have tested direct stenting. Hamon et al ${ }^{36}$ reported the outcome of 122 "carefully selected" patients. He confirmed that factors such as calcification and tortuosity need to be taken into account when direct stenting is considered. Procedural success was $96 \%$. In five patients it was not possible to deliver the stent through the undilated lesion, the stent having been lost in the peripheral circulation in two patients. The authors rightly reported the need for a controlled direct stent implantation or stent implantation after balloon predilatation. Patient selection was part of the inclusion criteria of the study (patients $>75$ years old and with heavily calcified lesions, bifurcations, total occlusions, left main lesions, and very tortuous vessels were excluded). Direct stenting was successful in $96.8 \%$. No stent was lost. The immediate postprocedural angiographic results were similar with both techniques. In line with other studies fluoroscopy and procedural times were significantly lower in direct stenting $(6.4(0.3)$ and $21(0.9)$ minutes $v 9.1(0.4)$ and 27.5 ( 1.1 ) minutes, respectively, $\mathrm{p}>0.001) .{ }^{38}$ MACE during hospitalisation were $1 \%$ in direct and $4 \%$ in predilated stenting $(p=0.05)$ and there were no significant differences at one, six, and 12 months' follow up. Restenosis rate at six months was $16.5 \%$ in direct stenting and $14.3 \%$ in predilated stenting (not significant). In a second study similar results were found. ${ }^{39}$ Here 411 patients (425 lesions) were randomly assigned at seven sites to undergo direct (210 patients, 216 lesions) or conventional (201 patients, 209 lesions) stent implantation. Lesions with severe calcification were also excluded in this study. Angiographic success rate was $100 \%$ in the direct stent group $(2.8 \%$ requiring balloon predilatation) and $98.6 \%$ in the predilatation group $(\mathrm{p}=0.12)$. Fewer balloons were used in the direct stent group (0.15 $v 1.09$ balloons/lesion treated) with a trend towards a reduction of procedure time (22.7 (15.0) $v 25.6$ (18.2) minutes, $\mathrm{p}=0.073$ ). In this study, however, fluoroscopy time and contrast volume were not different between groups. MACE-free survival at six months was $87.5 \%$ among patients who underwent the direct stent technique and $85.5 \%$ among patients who underwent predilatation.

Unpublished data from a UK study (the SLIDE trial) indicate that $94 \%$ of direct stented patients achieved a $<30 \%$ residual diameter stenosis, with no difference in six month MACE between the direct and predilatation groups $(7.1 \% v$ $6.7 \%)$. The direct stent strategy resulted in significantly less balloon use $(p<0.001)$ and in $80 \%$ the stent delivery system was the sole treatment strategy ( $\mathrm{R}$ Stables, personal communication, 2004).

In general this and the other published studies suggest that, if the operator feels a lesion is suitable for direct stent deployment and uses this approach, then this is a safe and cost saving exercise, although clinical outcome is similar. It is likely that until stents are as trackable and have as low a profile as balloons, direct stenting will never be an option for all patients. Direct stenting is used in about $30 \%$ of all patients in the UK. It appears compatible with the radial approach. ${ }^{40}$ A recently presented study confirmed the value of direct stenting and importantly indicated that the restenosis rates when care was taken in interventional techniques was lower than historical rates with predilatation and not far above levels achieved with drug eluting stents. That study emphasises that there is no substitute for careful stenting.

\section{Adjunctive pharmacotherapy}

Agents given around the time of the procedure are designed to improve the acute outcome rather than to reduce the long term restenosis rates; indeed, no studies have shown value from any drug given systemically at the time of PCI on late restenosis.

Antiplatelet agents in the form of aspirin and clopidogrel have become standard treatment. ${ }^{41}{ }^{42}$ Most patients are given the agent postprocedurally in accordance with the CLASSICS trial, although some preclinical (animal) data suggest increased benefit from pretreatment. ${ }^{42}$ In the CREDO study over 2000 patients were randomly allocated to receive a $300 \mathrm{mg}$ clopidogrel loading dose $(\mathrm{n}=1053)$ or placebo ( $\mathrm{n}=1063$ ) 3-24 hours before PCI. Thereafter, all patients received clopidogrel $75 \mathrm{mg} /$ day for 28 days; from day 29 until 12 months, patients in the loading dose group received clopidogrel $75 \mathrm{mg} /$ day and those in the control group received placebo. Clopidogrel pretreatment did not significantly reduce the combined risk of death, MI, or urgent target vessel revascularisation at 28 days (reduction 18.5\%, 95\% CI -14.2 to $41.8, p=0.23)$. However, in a prespecified subgroup analysis, patients who received clopidogrel at least six hours before PCI experienced a relative risk reduction of $38.6 \%$ (95\% CI -1.6 to $62.9, \mathrm{p}=0.051$ ) for the combined end point compared with no reduction with treatment less than six hours before PCI. At one year, long term clopidogrel treatment was associated with a $26.9 \%$ relative reduction in the combined risk of death, MI, or stroke (95\% CI 3.9 to $-44.4, \mathrm{p}=0.02$, absolute reduction 3\%). ${ }^{43}$ Increasingly, operators are pretreating their routine patients, often through preadmission clinics. In the ISAR-REACT trial, patients with stable angina were all given $600 \mathrm{mg}$ of clopidogrel and then randomly allocated to either abciximab or placebo. ${ }^{44}$ There 
Guide to cited studies

\begin{tabular}{|c|c|}
\hline ADMIRAL & $\begin{array}{l}\text { Abciximab before direct angioplasty and stenting in myocardial infarction regarding } \\
\text { acute and long term follow-up }\end{array}$ \\
\hline AMIST & Angioplasty versus minimally invasive surgery trial \\
\hline ARTS & Arterial revascularization therapies study \\
\hline ASPECT & Asian paclitaxel-eluting stent clinical trial \\
\hline ASSENT-3 & Assessment of the safety and efficacy of a new thrombolytic \\
\hline ASSENT IV & $\begin{array}{l}\text { Assessment of the safety and efficacy of a new treatment strategy for acute myocardial } \\
\text { infarction }\end{array}$ \\
\hline BESMART & Bestent in small arteries \\
\hline BETACATH & BETACATH Registry \\
\hline C-SIRIUS & Canadian sirolimus eluting stent in coronary lesions \\
\hline CACHET & Comparison of abciximab complications with Hirulog for ischemic events trial \\
\hline CADILLAC & Controlled abciximab and device investigation to lower late angioplasty complications \\
\hline CHOICE-AMI & CHOICE acute mycardial infarction trial \\
\hline CLASSICS & Clopidogrel aspirin stent international cooperative study \\
\hline CREDO & Clopidogrel for the reduction of events during observation \\
\hline DANAMI-2 & $\begin{array}{l}\text { Danish multicentre randomized study on fibrinolytic therapy versus acute coronary } \\
\text { angioplasty in acute myocardial infarction }\end{array}$ \\
\hline DEFER & $\begin{array}{l}\text { Deferral versus performance of PTCA based on coronary pressure derived fractional flow } \\
\text { reserve }\end{array}$ \\
\hline $\begin{array}{l}\text { DELIVER-1 } \\
\text { DELIVER-2 }\end{array}$ & $\begin{array}{l}\text { Non-polymer based paclitaxel-coated coronary stent for the treatment of patients with de } \\
\text { novo coronary lesions trials: I and II }\end{array}$ \\
\hline E-SIRIUS & European sirolimus eluting stent in coronary lesion \\
\hline ELUTES & European evaluation of paclitaxel eluting stent \\
\hline ENDEAVOR ॥ & $\begin{array}{l}\text { Randomized trial to evaluate the safety and efficacy of the Medtronic AVE ABT-578 eluting } \\
\text { driver coronary stent in de novo native coronary artery lesions: II }\end{array}$ \\
\hline ERACI-II & $\begin{array}{l}\text { Argentine randomized trial of percutaneous transluminal coronary angioplasty versus } \\
\text { coronary artery bypass surgery in multivessel disease }\end{array}$ \\
\hline ESPRIT & European study of prevention of reocclusion after initial thrombolysis \\
\hline FINESSE & Facilitated intervention with enhanced reperfusion speed to stop events \\
\hline FUTURE & First use to underscore reduction in restenosis with everolimus \\
\hline GUSTO llb & Global use of strategies to open occluded coronary arteries in acute coronary syndromes \\
\hline INHIBIT & Intimal hyperplasia inhibition with beta in-stent restenosis trial \\
\hline ISAR & Intracoronary stenting and antithrombotic regimen trial \\
\hline ISAR-REACT & $\begin{array}{l}\text { Intracoronary stenting and antithrombotic regimen rapid early action for coronary } \\
\text { treatment }\end{array}$ \\
\hline ISAR-SMART & Intracoronary stenting or angioplasty for restenosis reduction in small arteries \\
\hline MERLIN & Middlesbrough early revascularisation to limit infarction \\
\hline NICE-3 & National investigators collaborating on enoxaparin-3 \\
\hline PAMI & Primary angioplasty in myocardial infarction \\
\hline PRAGUE & $\begin{array}{l}\text { Primary angiography in patients transferred from general community hospitals to } \\
\text { specialized PTCA units with or without emergency thrombolysis }\end{array}$ \\
\hline PRAGUE-2 & $\begin{array}{l}\text { Primary angioplasty in acute myocardial infarction patients from general community } \\
\text { hospitals transported for percutaneous transluminal coronary angioplasty units versus } \\
\text { emergency thrombolysis }\end{array}$ \\
\hline RAVEL & $\begin{array}{l}\text { Randomized study with sirolimus coated BX velocity balloon expandable stent in the } \\
\text { treatment of patients with de novo native coronary lesions }\end{array}$ \\
\hline REACT & Rescue angioplasty versus conservative management of thrombolysis \\
\hline RENO & European registry of intraluminal coronary beta brachytherapy \\
\hline REPLACE 2 & Randomized evaluation in $\mathrm{PCl}$ linking Angiomax to reduced clinical events \\
\hline SAFER & Saphenous vein graft angioplasty free of emboli randomized trial \\
\hline SCORE & Study to compare restenosis rate between quest and quads-QP2 \\
\hline SCRIPPS & Scripps coronary radiation to inhibit proliferation post stenting \\
\hline SHOCK & Should we emergently revascularise occluded coronaries for cardiogenic shock \\
\hline SIRIUS & $\begin{array}{l}\text { Sirolimus eluting balloon expandable stent in the treatment of patients with de novo native } \\
\text { coronary artery lesions }\end{array}$ \\
\hline SISCA & Stenting in small coronary arteries \\
\hline SISR & $\begin{array}{l}\text { Sirolimus-eluting Bx velocity stent versus intravascular brachytherapy in the treatment of } \\
\text { patients with in-stent restenotic coronary artery lesions }\end{array}$ \\
\hline SLIDE & Selected lesion indication for direct stenting \\
\hline sOS & Stent or surgery \\
\hline SPEED & Strategies for patency enhancement in the emergency department \\
\hline START & Stents and radiation therapy \\
\hline STOP-AMI 1 & $\begin{array}{l}\text { Stent versus thrombolysis for occluded coronary arteries in patients with acute myocardial } \\
\text { infarction }\end{array}$ \\
\hline SYNTAX & Synergy between PCI with TAXUS and cardiac surgery \\
\hline TACTICS T & $\begin{array}{l}\text { Treat angina with Aggrastat and determine cost of therapy with an invasive or } \\
\text { conservative strategy. Thrombolysis in myocardial infarction }\end{array}$ \\
\hline TARGET & Do tirofiban and Reopro give similar efficacy outcome trial \\
\hline TASTE & Ticlopidine aspirin stent evaluation \\
\hline TAXUS & Treatment of de novo coronary disease using a single paclitaxel eluting stent \\
\hline TIMI & Thrombolysis in myocardial infarction \\
\hline TOAST-GISE & Total occlusion angioplasty study-Società Italiana di Cardiologia Invasiva \\
\hline ULTIMA & Unprotected left main trunk intervention multi-center assessment \\
\hline
\end{tabular}


was no difference in MACE between the two groups other than an increase in bleeding in the patients who were given abciximab. Whether $600 \mathrm{mg}$ preprocedurally is more effective in higher risk patients such as those with less stable angina who have not had the chance to be preloaded or whether those patients already taking a maintenance dose of $75 \mathrm{mg}$ because of a previous admission for ACS benefit from topping up at the time of intervention are important questions still to be answered in appropriate trials.

There have been some studies and debate on the importance, incidence, and cause of clopidogrel resistance. In a study by Muller et $a l^{45}$ of patients treated with $600 \mathrm{mg}$ clopidogrel up to $11 \%$ were defined as non-responders and up to $26 \%$ as semi-responders, although these definitions were based on in vitro laboratory platelet aggregation responses. Initial concerns that certain statins that are substrates of the CYP3A4 isoform competitively inhibit the metabolic activation of clopidogrel appear not to have been confirmed. ${ }^{46-48}$

Postprocedural administration of clopidogrel for more than one month in higher risk patients (for example, those with unstable coronary syndromes, LMS, postvascular brachytherapy, or bifurcations) is empirical but thought to be best practice. For drug eluting stents the drug is given according to the instructions for use (three months for Cypher and six months for TAXUS stents). Clopidogrel is generally well tolerated with a side effect rate of $<3 \%$. There appears to be no cross reaction between the side effects of clopidogrel and of ticlopidine, so patients unable to tolerate the clopidogrel can try ticlopidine, although historical evidence suggests that regular blood monitoring for neutropenia and thrombocytopenia is required with ticlopidine use. Patients unable to tolerate thienopyridines can be considered for treatment with aspirin alone or additional subcutaneous heparin for one month (TASTE study) depending on the risk of stent thrombosis.

Controversy still surrounds some aspects of the glycoprotein IIb/IIIa inhibitors. PCI disrupts plaques and the incidence of events is reduced with glycoprotein IIb/IIIa inhibitors. Whether the enzyme release has true longer term clinical significance (causing "enzyme bumps" or prognostically important microinfarcts) has been much debated. High concentrations of standard enzyme markers are associated with worse in-hospital and subsequent mortality and, perhaps not surprisingly, a lower incidence of target vessel revascularisation. ${ }^{49}$ It is generally believed that such concentrations will be obvious to the operator from the clinical setting and in such circumstances glycoprotein IIb/ IIIa inhibitors will be used in accordance with the trial data of the mid- and late 1990s. ${ }^{50}{ }^{51}$ It is more difficult to judge the importance of smaller rises in enzymes; most are probably the result of side branch occlusion or microembolic events. ${ }^{52}$ Since the enzyme rise is only identified after what will appear to have been a successful procedure, the degree to which such agents should be used peri- and preprocedurally in routine cases remains unclear. Certainly the threshold for their use has fallen, not least since up to $50 \%$ of patients in some centres are there because of ACS and only patients with obviously apparently uncomplicated PCI will not receive glycoprotein IIb/IIIa inhibitors. Perhaps not surprisingly an increase in concentrations of more sensitive markers (for example, troponin I) appear not to be associated with longer term MACE. ${ }^{53} 54$

Which agent should be used during PCI has been resolved by several trials. While all three available agents have shown benefit compared with placebo, the TARGET trial appeared to show superiority of abciximab over tirofiban. ${ }^{55}$ At 30 days the primary end point showed a significantly better outcome with abciximab, with a $1.6 \%$ absolute and $26 \%$ relative reduction in the composite of death, MI, and any target vessel revascularisation. However, by six months these differences had been reduced to a $0.5 \%$ absolute and $4 \%$ relative reduction..$^{56}$ Despite this narrowing of effect and even a trend towards benefit in diabetic patients in the tirofiban group, the early difference remains clinically important and indeed abciximab is the only drug licensed in planned angioplasty. Glycoprotein IIb/IIIa receptor blockade (abciximab) is mandated in diabetic patients undergoing PCI. ${ }^{57}$ The ESPRIT trial, designed as a planned PCI study, showed benefit only in the unstable angina group (stable angina group: $25 \%$ reduction in $7.2 \% v 5.4 \%, \mathrm{p}=0.29$; ACS group: $>2$ day $48 \%$ reduction in $11.1 \% v 5.7 \%, \mathrm{p}=0.013) .{ }^{58}$ Higher risk patient (ACS, ECG changes, and troponin positive) should start treatment with a glycoprotein IIb/IIIa inhibitor, and transfer (if required) for intervention during the infusion period is the ideal option; if the patient cannot be transferred during that time then a decision about whether to reinitiate glycoprotein IIb/IIIa inhibitors, probably with abciximab, will need to be taken. One aspect of treatment with antiplatelet agents is whether it is necessary to have clopidogrel and a glycoprotein IIb/IIIa inhibitor. In a retrospective analysis of the TARGET trial clopidogrel appeared to add to the value of glycoprotein IIb/ IIIa inhibitors irrespective of type and particularly if prescribed preprocedurally. ${ }^{59}$

Newer antithrombotic agents used during the PCI procedure instead of heparin (such as the hirudin derivatives) are being tested. In a large phase III study of patients with unstable angina undergoing PCI, the thrombin specific anticoagulant bivalirudin produced relative risk reductions of $22 \%(p=0.039)$ for ischaemic complications and $62 \%$ $(p<0.001)$ for bleeding complications compared with heparin..$^{60}$ An ongoing trial is aimed at determining the efficacy and safety of heparin with planned glycoprotein IIb/ IIIa versus bivalirudin with provisional glycoprotein IIb/IIIa treatment. In a pilot dosing study (the CACHET trial) 268 patients who underwent coronary intervention were randomly assigned in three sequential phases to treatment with bivalirudin (with or without abciximab) or the control regimen consisting of low dose weight adjusted heparin with abciximab. ${ }^{61}$ Patients in the bivalirudin arms received bivalirudin $(1.0 \mathrm{mg} / \mathrm{kg}$ bolus, infusion of $2.5 \mathrm{mg} / \mathrm{kg} / \mathrm{h}$ for four hours) plus abciximab in phase A, bivalirudin $(0.5 \mathrm{mg} /$ $\mathrm{kg}$ bolus, infusion of $1.75 \mathrm{mg} / \mathrm{kg} / \mathrm{h}$ for the procedure duration) plus provisional (rescue) abciximab in phase $\mathrm{B}$, or bivalirudin $(0.75 \mathrm{mg} / \mathrm{kg}$ bolus, infusion of $1.75 \mathrm{mg} / \mathrm{kg} / \mathrm{h}$ for the procedure duration) plus provisional abciximab in phase C. Abciximab was elected to be used provisionally in $24 \%$ of the patients in the bivalirudin arms of phases B and C. A composite clinical end point of death, MI, repeat revascularisation, or major bleeding by seven days occurred in $3.3 \%, 5.9 \%, 0 \%$, and $10.6 \%$ of the patients in the bivalirudin phase A, bivalirudin phase $\mathrm{B}$, bivalirudin phase $\mathrm{C}$, and heparin plus planned abciximab arms (control arm), respectively ( $p=0.018$ for the pooled bivalirudin groups versus the heparin group).

In the recently completed REPLACE 2 study patients were randomly assigned to receive intravenous bivalirudin $(0.75 \mathrm{mg} / \mathrm{kg}$ bolus plus $1.75 \mathrm{mg} / \mathrm{kg} / \mathrm{h}$ for the duration of PCI) with provisional glycoprotein IIb/IIIa inhibition ( $\mathrm{n}=2999)$ or heparin (65 U/kg bolus) with planned glycoprotein IIb/IIIa inhibition (abciximab or eptifibatide) $(\mathrm{n}=3011)$. No group was treated with heparin and provisional IIb/IIIa inhibitors. The results showed no difference in the two groups, with the primary composite end point being reached at 30 days by $9.2 \%$ of patients in the bivalirudin group and by $10.0 \%$ of patients in the heparin plus glycoprotein IIb/IIIa group $(p=0.32)$. In-hospital major bleeding rates were significantly lower in the bivalirudin group $(2.4 \% v 4.1 \%, \mathrm{p}<0.001)$. Bivalirudin with 
provisional glycoprotein IIb/IIIa blockade apparently is not inferior to heparin plus planned glycoprotein IIb/IIIa blockade during contemporary PCI but importantly is associated with less bleeding.

The use of low molecular weight heparin in PCI is still unresolved, since we are in an era of its increasing use for ACS, and more patients are going to present for PCI when they are already receiving low molecular weight heparin. Low molecular weight heparin appears to be effective and safe even in combination with glycoprotein IIb/IIIa inhibitors. ${ }^{63}$ Since the last guidelines were made available, the final NICE3 trial data have been published. ${ }^{64}$ This study was an open label safety observational evaluation of enoxaparin in combination with any one of the three available glycoprotein IIb/IIIa antagonists in patients presenting with non-ST elevation ACS. Of 628 patients, 283 underwent PCI. The 30 day incidence of non-CABG major bleeding was $1.9 \%$ and was not significantly higher than a prespecified historical control rate of $2.0 \%$, suggesting that if the patient has started low molecular weight heparin preprocedurally in the setting of ACS then heparin can be continued throughout the PCI. However, the lack of reversibility, lack of easy near patient monitoring, and degree to which anticoagulation can be adjusted compared with unfractionated heparin may cause problems for the surgeon in those occasional cases when an inpatient requires surgery.

\section{Adjunctive equipment \\ Intravascular ultrasound}

Despite its value in visualising true lumen dimensions, vessel wall composition, and the absolute effects of intervention, IVUS remains a niche product. IVUS should, however, be available in all catheterisation laboratories for the times when it may be clinically useful-for example, to assess the result of LMS stenting, for evaluation of complex lesions, to help establish the best method of treating in-stent restenosis, or occasionally for ambiguous angiography. IVUS has become an indispensable research tool in the analysis of new treatment strategies such as coronary brachytherapy, for the assessment of late remodelling or malapposition of drug eluting stents, and to study drug effects-for example, plaque regression with lipid lowering treatment.

\section{Capture devices}

PCI in degenerate vein grafts is associated with a high incidence of enzyme release and at times the no reflow phenomenon. Some devices have become available that are designed to be positioned distal to and before the stent placement, some of which show benefit. In a recently published trial, the SAFER study, outcome (in terms of enzyme defined MI) was better if a distal protection device was used. In this study 800 patients were randomly allocated to either the PercuSurge protection device or no protection device; the results were striking. The incidence of the primary end point (MACE combined a clinical end point defined as death, Q wave or non-Q wave MI, emergency bypass surgery, or repeat target vessel revascularisation) in the PercuSurge group was $50 \%$ less than in the control group during the inpatient stay and at 30 days (cumulative MACE to 30 days for the protection device $9.9 \% v$ control $19.8 \%, p=0.001$ ). The end point was driven by a lower incidence of non-Q wave infarcts, and perhaps not surprisingly the incidence of enzyme rise more than three times normal was also significantly reduced. Clinical benefit was seen even when platelet glycoprotein IIb/IIIa receptor blockers were administered (61\% of patients), with composite end points occurring in $10.7 \%$ of protection device patients versus $19.4 \%$ of control patients $(\mathrm{p}=0.008){ }^{65}$
Several distal protection devices are coming on to the market. Balloon/aspiration systems and filter wire systems appear to be equally effective. ${ }^{66}$ Issues surrounding their use include perception of need, cost effectiveness, and ease of use.

\section{Cutting balloons}

Some data support the primary use of the cutting balloon in small vessels and in patients with in-stent restenosis; the cutting balloon clearly performs better than balloon angioplasty alone with re-restenosis rates in long diffuse lesions of $27 \%{ }^{67}{ }^{68}$ The cutting balloon is likely to be superseded by drug eluting stents but may be retained as a device that limits balloon movement and therefore injury before intravascular brachytherapy or before deployment of drug eluting stents within in-stent lesions where routine balloon movement can lead to excessive balloon mediated endothelial injury.

\section{Pressure wires}

The value of the pressure wire, the physiological basis of which has been well established, in lesions of intermediate severity has been confirmed by several studies. In the DEFER study fractional flow reserve (FFR) was measured in 325 patients with lesions without otherwise clear evidence of ischaemia; if the FFR was $>75 \%$, patients were randomly assigned to no treatment (the defer group) or intervention. ${ }^{69}$ Event-free survival (89\% $v 83 \%$ at 24 months) and the incidence of angina did not differ between the groups. In such intermediate lesions FFR may therefore help determine who should receive interventional treatment. It has recently been reported that FFR predicts longer term outcome after stenting; in 750 patients assessed by multivariate analysis, FFR immediately after stenting was the most significant independent variable related to all types of events. ${ }^{70}$ In $36 \%$ of the patients, FFR normalised $(>0.95)$ and event rate was $4.9 \%$ in that group; in $32 \%$ of the patients, poststenting FFR was between 0.90 and 0.95 and event rate was $6.2 \%$; in $32 \%$ of patients, poststenting FFR was $<0.90$ and event rate was $20.3 \%$; and in $6 \%$ of the patients, FFR was $<0.80$ and event rate was $29.5 \%(\mathrm{p}<0.001)$. Therefore, if there is doubt about stent result use of the pressure wire should be considered.

Use of the pressure wire for determining FFR appears to be becoming increasingly popular since it is safe, objective, and reliable and allows non-intervention in specific intermediate lesion subsets. Debate continues over the value of intracoronary bolus or continuous adenosine infusion, the latter being particularly helpful in diffuse disease where decisions about spot stenting site(s) need to be made.

\section{$\mathrm{PCI}$ and ACS (non-ST elevation MI)}

It is generally agreed that higher risk patients with non-ST segment elevation MI should receive glycoprotein IIb/IIIa inhibitors and then undergo diagnostic coronary arteriography and PCI if appropriate. The data to support this exist but the TACTICS TIMI 18 study has been criticised for having a different cut off enzyme rise definition between those patients randomly allocated to intervention and those allocated to conservative treatment, thus favouring intervention. ${ }^{71}$ European and British guidelines, however, recommend angiography early for such patients. ${ }^{72}$ Evidence for the use of glycoprotein IIb/IIIa inhibition in PCI for non-ST elevation MI (abciximab) has been well established.

\section{$\mathrm{PCl}$ in ST segment elevation acute $\mathrm{MI}$}

Outcome after acute coronary occlusion is dependent on whether the artery remains closed (TIMI grade 0 ) or becomes fully patent (TIMI grade III), or where flow is incompletely restored (TIMI grade I-II). Attainment of TIMI grade III flow has been shown to reduce short and medium term mortality 
by up to $50 \%$ compared with other grades of TIMI patency but can be achieved by only $50-60 \%$ of patients treated with thrombolytic agents. The only treatment shown to be better than thrombolysis in this regard is primary PCI. A number of studies, albeit with variable numbers, have shown that if a patient can be taken to the catheterisation laboratory within 12 hours of the onset of pain (and within two hours of arrival in hospital) and the artery successfully opened and the stenosis dilated then TIMI grade III flow can be obtained in $80-97 \%$ of patients; short and long term survival and morbidity have been shown to be improved in such cases compared with thrombolysis. ${ }^{73}$

Reocclusion of the vessel remains a real problem with thrombolytic treatment $(30-40 \%$ by $3-6$ months); the comparable 3-6 month vessel patency after primary angioplasty is much higher ( $87 \%$ to $91 \%$ ). ${ }^{74}$ Early pooled data from the various thrombolytic trials not surprisingly suggest a worse longer term outcome with lysis than with primary angioplasty (death: $6.4 \% \vee 2.5 \%$; reinfarction: $7.9 \% \vee 2.0 \%$; stroke: $2.5 \%$ v $0.3 \%$; and death or reinfarction: $13.1 \% v 4.3 \%$, respectively). Recurrent ischaemia in the three comparative and early trials (Mayo Clinic, PAMI, and Zwolle) varied between $27 \%$ and $36 \%$ for thrombolytic treated patients and between $9 \%$ and $15 \%$ for patients who had primary PCI. The two year event-free survival (that is, no MI, cardiac death, or need for reintervention) for the PAMI I trial patients is reported to be $85 \%$, indicating that the early separation of the outcome curves for thrombolytic treated and angioplasty treated patients is maintained. Treating the underlying stenosis as well as "rescuing" any patient who has not reperfused is the likely mechanistic benefit of intervention.

A recent meta-analysis has confirmed the clear benefit of primary angioplasty compared with in-hospital lysis. ${ }^{75}$ It is clear from these data that mortality, non-fatal acute MI, or the combination of death, non-fatal acute MI, and stroke is significantly reduced in the primary PCI patients. Mortality, for example, is reduced by an absolute $2 \%$ ( $>25 \%$ relative reduction, $\mathrm{p}<0.001)$; there were no haemorrhagic strokes in the intervention arm $(p<0.0001)$.

While benefits in terms of mortality may be less with primary PCI than with fibrin specific lytics, there is still an absolute benefit in favour of primary PCI $(1.6 \%, \mathrm{p}<0.021){ }^{75}$ Other meta-analyses for primary PCI have been evaluated on the basis of high and low risk patients. Higher risk patients (older age, larger infarcts, and anterior infarcts) appear to benefits from primary angioplasty specifically in terms of both mortality and reinfarction, whereas the low risk group benefits predominantly in terms of reinfarction. One trial considered alone from the pooled data, the GUSTO IIb study, found no longer term benefit and is often quoted for this. ${ }^{76}$ This was due in part to less than optimal PCI technique (as shown by the percentage of patients with TIMI grade III flow), inclusion of low volume centres, and what may be regarded as prolonged door to balloon inflation times; contemporary data suggest that this needs to be less than 120 minutes. More recent trials in which stenting has been employed have shown significant improvement in immediate patency rates, which may also be an important factor, since stents were used infrequently in GUSTO II.

The biggest problem with the interventional treatment of acute MI is the mismatch between the availability of intervention facilities and where patients normally present-that is, to non-interventional centres.

\section{What makes for effective primary $\mathrm{PCI}$ ?}

Even when patients do present to an interventional centre the same factors that influence benefit in thrombolytic treatment need also to be considered in primary angioplasty. Thus, a large study Cannon et $a l^{77}$ found that among 27080 patients treated with primary angioplasty, the door to balloon time was a significant factor in predicting mortality outcome (adjusted mortality odds ratio $1.41,95 \%$ CI 1.08 to -1.84 , $\mathrm{p}=0.01$ for door to balloon time $>2$ hours and odds ratio $1.61,95 \%$ CI 1.25 to $-2.08, \mathrm{p}<0.001$ for $>3$ hours compared with $<2$ hours).

Use of stents in primary PCI undoubtedly influences outcome. In a small study Maillard et $a l^{78}$ found that six month event-free survival rates were $81.2 \%$ in stented patients versus $72.7 \%$ in those treated with balloon alone. This was confirmed by the Beaumont Hospital group, who studied patients whose infarcts were treated primarily only with PCI. The acute result was significantly better in the stented group. The six month event-free survival rate was also higher in the stented group $(12.6 \%, \mathrm{n}=452 v$ PTCA $20.1 \%, \mathrm{n}=448, \mathrm{p}<0.01)$. Further, the volume of primary angioplasty procedures undertaken appears to be an important factor influencing outcome. ${ }^{79}$

That stent plus abciximab is better than lytic alone was shown in the STOP-AMI 1 trial (with a $62 \%$ relative reduction $-23.2 \%$ (tissue-type plasminogen activator) to $8.5 \%$ in the stent plus abciximab group).$^{80}$ In the ISAR study ${ }^{81}$ patients undergoing PCI within 48 hours of acute MI were randomised to abciximab or routine treatment (heparin). There was a $52 \%$ reduction in 30 day death, recurrent acute MI or any target vessel revascularisation in those randomised to abciximab (10.5-5.0\%). In the ASSENT-3 study clinical outcomes were compared in patients who received cotreatment with abciximab, enoxaparin, or unfractionated heparin and subsequently underwent an elective $(\mathrm{n}=1064)$ or urgent $(\mathrm{n}=716)$ PCI.

Clearly, primary angioplasty can be considered optimal when the door to balloon time is short $(<2$ hours), when optimal techniques are used (that is, stents), where the interventional centre and operator volume is high and where appropriate adjunctive treatment is used during the procedure (that is, glycoprotein IIb/IIIa inhibitors). With optimal treatment, mortality can be as low as $6 \%$. Improving primary PCI results still further may require additional drugs, perhaps even administering lytic to initiate opening of the artery so called facilitated PCI.

\section{Advantages of primary angioplasty}

Although an ongoing matter for debate, the direct angioplasty in acute MI has become increasingly compelling, particularly for patients presenting within 12 hours to a hospital with a catheterisation laboratory performing a high volume of procedures and able to treat patients within two hours of arrival at the hospital. ${ }^{35}$ In the early randomised trials primary PCI appeared at least as effective as thrombolysis with a significantly lower risk of stroke and a reduction in the high mortality risk associated with cerebral bleeding (stroke in primary PCI $0.7 \% v$ lytic treatment $2.0 \%$, odds ratio $0.35,95 \%$ CI 0.14 to $0.77, \mathrm{p}=0.007$; intracerebral haemorrhage in primary PCI $0.1 \% v$ lytic treatment $1.1 \%$, odds ratio $0.07,95 \%$ CI 0.0 to $0.42, p<0.001)$. These figures do not take into account current strategies that incorporate glycoprotein IIb/IIIa receptor blocker use, although the stroke rate with adjunctive treatment does not appear to have increased.

An important advantage of intervention is that it deals with the stenosis, which lytic agents cannot do. There are data to support the concept that the greater the residual stenosis the more likely the artery will reocclude. ${ }^{82}$ Failure of reperfusion is more likely with lytic agents when there is significant atheroma bulk or severe disruption of the plaque that is not stented.

Importantly, knowing the state of the coronary arteries allows for better triage of postinfarction patients. Thus, the normal 5-7 day inpatient stay may be reduced to 2-3 days if 
the infarct related artery is open and the status of the rest of the arteries is known.

\section{Problems with primary angioplasty}

Primary and rescue angioplasty may be being undertaken in patients who are unwell and the best outcomes require the most experienced operators. In a retrospective study Magid et $a l^{35}$ showed that the benefits of primary angioplasty outweighed those of thrombolysis in high and intermediate volume centres but not in low volume centres (mortality 3.4\% with primary PCI $v 5.4 \%$ with thrombolysis in high volume centres, $\mathrm{p}<0.001,6.2 \% \vee 5.9 \%, \mathrm{p}=0.58$ in low volume centres). Poor outcomes for patients with cardiogenic shock appear to be common irrespective of treatment. Lastly fewer cost effectiveness data are available on the contemporary interventional strategy with stents and glycoprotein IIb/IIIa receptor blockers than on the historical series when simple balloon angioplasty was used.

While better early patency rates can be achieved with primary PCI, which translates into improved short and medium term clinical outcome, this treatment is available to relatively few patients with acute MI because most patients are admitted to hospitals without interventional facilities. Either the availability of interventional facilities needs to be increased or patients should be pretreated with lytic or antiplatelet agents, or both, and transferred to an interventional facility.

\section{Facilitated primary $\mathrm{PCI}$}

Ross et $a l^{83}$ found that adjunctive lysis before angioplasty increased initial patency in patients receiving lytic agents (61\%) compared with $34 \%$ who received placebo. Angioplasty, however, dramatically increased TIMI III flow equally in both groups to $77 \%$ and $78 \% .{ }^{83}$ Other observational studies support the concept of a combination of (prehospitalisation) a lytic plus intervention ("facilitated" primary PCI). Juliard et $a l^{84}$, for example, have published data on 170 patients given a lytic before hospitalisation and 151 (61) minutes after the onset of chest pain. A 90 minute postlytic angiogram was recorded in all patients; this showed TIMI grade III patency in $64 \%$ and TIMI grade $0-\mathrm{I}$ in $29 \%$ $(\mathrm{n}=50)$. So called rescue angioplasty was successful in 49 of these 50 patients. Thus, overall TIMI grade III patency was achieved in $91 \%$ of all patients with TIMI grade II in $7 \%$ at an average of 113 (39) minutes after lytic administration and 55 (19) minutes after admission. The overall in-hospital mortality was $4.1 \%$ and was similar to that of a matched cohort of patients receiving primary angioplasty $(4.7 \%)$. This was not a randomised trial, but it does suggest that preadmission lysis may need angioplasty to achieve optimal patency and the combination may be no better than primary angioplasty alone. Additionally it confirmed the importance of TIMI flow, since those who had achieved TIMI grade III flow during the acute phase also had a low mortality (3\%). Loubeyre et $a l^{85}$ also undertook an observational study in which the outcome of patients who received out of hospital lysis plus immediate angiography and intervention if needed (148 of 1010 admitted patients) was reviewed. Only 49\% of these patients had TIMI grade III patency, which increased to $92 \%$ with angioplasty; in-hospital mortality was $4.9 \%$. Interestingly, in support of the need to treat the underlying lesion the two year freedom from death and reinfarction was $90 \%$ and freedom from death, reinfarction, and target vessel revascularisation was $83 \%{ }^{85}$

\section{Facilitated primary $\mathrm{PCl}$ with glycoprotein IIb/IIIa inhibitors alone}

The options for adjunctive treatment are glycoprotein IIb/IIIa alone, half dose lytic alone, or the combination of both before
PCI. The ADMIRAL trial showed a clear reduction in end point (death, recurrent acute MI, and need for urgent revascularisation) in those patients randomly assigned to a glycoprotein IIb/IIIa inhibitor compared with placebo $(7.4 \% \mathrm{v}$ $15.9 \%, \mathrm{p}<0.02) .{ }^{86}$ In this study the benefit at six months was significantly better (89\% reduction, $23.7 \% \vee 2.5 \%$, $\mathrm{p}=0.005)$ only in those patients receiving glycoprotein IIb/IIIa from a "mobile intensive care team" who visited the patient. Patients who received the glycoprotein IIb/IIIa in the coronary care unit or catheterisation laboratory obtained no benefit at six months ( $13.3 \%$ in placebo $v 9.2 \%$ in treated patients, not significant). This would mean a major change in UK policy for delivery of treatment in terms of complex training issues for paramedic ambulance staff. This study emphasises the importance of reducing time delay. The CADILLAC study obtained less convincing results with glycoprotein IIb/IIIa; patients were randomly assigned to stenting plus abciximab, stenting alone, balloon plus abciximab, or balloon alone. ${ }^{87}$ The primary end point (death, repeat MI, disabling stroke, or ischaemia driven target vessel revascularisation at six months) was reached by $10.8 \%$, $10.9 \%, 20 \%$, and $20 \%$ of patients, respectively, suggesting that stenting is superior to balloon but that abciximab did not improve clinical outcome. The differing results from those seen in ADMIRAL have been hotly debated but probably relate to differences in patient selection, although the speed of getting the agent to the patient may have had a role.

\section{Facilitated primary $\mathrm{PCl}$ with half dose lytic alone}

The published studies consist of those observational data referenced above, which do intimate some benefit from prePCI administration of half dose lytic. A recently presented study in which tenecteplase was given before angioplasty reported a higher TIMI grade III incidence at baseline (59\% $\mathrm{v}$ $14 \%, \mathrm{p}<0.001)$ compared with primary PCI alone, although as with other studies this equalised after PCI. ${ }^{88}$ The clinical outcomes were no different, but one interesting aspect was that the lack of differences occurred despite the PCI in the facilitated arm being undertaken a mean of 12 hours after tenecteplase administration (compared with 180 minutes from symptoms to onset in the primary PCI arm). Thus, the lytic appears to have allowed delayed PCI to be as effective as primary PCI; there were no differences in measures of bleeding.

\section{Facilitated primary $\mathrm{PCl}$ with glycoprotein IIb/IIla inhibitors plus half dose lytic}

There are data to support the use of glycoprotein IIb/IIIa plus lytic before intervention, but these studies also add weight to the argument for the use of primary PCI in acute MI. In the SPEED (GUSTO-4 pilot) trial, which was reported in 2000, 323 patients underwent primary PCI at a median time of 63 minutes after onset of glycoprotein IIb/IIIa treatment with or without half dose lytic. ${ }^{89}$ Patients who underwent PCI had an odds ratio of 0.46 (CI 0.24 to $0.87, \mathrm{p}<0.02$ ) for the combined end point (death and recurrent acute MI) compared with those who did not undergo primary PCI. Excess bleeding was a problem with this adjunctive combination; the incidence of major bleeding was $2.7 \%$ in the glycoprotein IIb/IIIa alone group and $3.6 \%$ in the half dose reteplase group but reached $8.8 \%$ in the combined group. These figures were paralleled by the need for blood transfusion in increased numbers of the combined group; such a strategy of pre-hospitalisation lytic or glycoprotein IIb/ IIIa treatment would clearly be difficult to achieve with respect to paramedic staff training.

The data suggest that primary PCI continues to be the best option if it can be achieved quickly, but outcome may be optimised by the addition of preprocedural adjunctive 
treatment administered when primary PCI cannot be delivered within an acceptable time frame. Getting the patient as quickly as possible to interventional facilities is critical for achievement of the highest patency rates.

\section{Patient transfer for primary $\mathrm{PCl}$}

Patient transfer may be particularly applicable in health care systems where interventional facilities are less available as a first line because of geography or historical development (as in the UK).

In the PRAGUE-1 study patients were randomly assigned to lytic treatment at a primary reception hospital, a lytic en route to primary PCI, or transfer for primary PCI alone. ${ }^{90}$ Significantly fewer patients who received primary PCI reached the combined end point (death, non-fatal acute MI, and revascularisation; $30 \%, 18 \%$, and $16 \%$, respectively, $\mathrm{p}<0.05)$. In the PRAGUE-2 study transfer for primary angioplasty (for up to $120 \mathrm{~km}$ ) was shown to be a better option than immediate lysis (the composite end point for immediate thrombolytic was $15.2 \% \quad v \quad 8.4 \%$ for those transferred for primary PCI, $p=0.003) .{ }^{91}$ DANAMI-2 randomly allocated patients to primary PCI or fibrinolysis with transfer if necessary. ${ }^{92}$ The transfer time in this Danish study was less than three hours; transfer directly to the PCI centre was less than one hour by ambulance; and the symptom to hospital and door to needle times were two hours and less than one hour, respectively. Primary PCI did better than lysis in terms of combined end point and reinfarction (but not mortality), even for patients presenting to the referral hospital and requiring transfer (combined end point for referring hospital $8.5 \% v 14.2 \%, p=0.002$ and $8.0 \%$ $v 13.7 \%, \mathrm{p}=0.0003$ for those presenting to the PCI centre). Such trials suggest that patients who undergo primary PCI can have better outcomes even if they need to be transferred.

The FINESSE and ASSENT-IV studies will assess the benefit of adjunctive pre-primary PCI treatment on outcome of primary PCI in acute MI. The CHOICE-AMI study is a planned UK study comparing pre-hospital thrombolysis with facilitated PCI.

The value of rescue PCI in acute MI is undetermined despite its intuitive appeal but is being tested in two UK studies that have recently been completed (REACT and MERLIN). Early data from MERLIN presented or published in abstract form suggest that the benefit from rescue angioplasty is driven by reduced subsequent revascularisation rates.

\section{Drug eluting stents}

The development of drug eluting stents has made a significant impact on in-stent restenosis. Two of the three aspects of restenosis with stents (recoil and negative remodelling) having been resolved, the vessel wall tissue response to PCI injury remained an important clinical issue. Innovative registry data from Morice et a $l^{93}$ with small numbers of patients showed the benefit of rapamycin eluting stents and paved the way for appropriately sized randomised clinical trials. Thus, the RAVEL study has shown that patients randomly assigned to the control arm had 26\% angiographic restenosis, whereas those receiving a rapamycin (sirolimus) eluting stent had a restenosis rate of $0 \%$. Late loss was $-0.01 \mathrm{~mm}$ confirming the effect of the drug on the tissue response. ${ }^{93}$ The lesions tested in the RAVEL study were simple, as the study was designed to test proof of principle. The SIRIUS trial suggests that this stent-drug combination is also effective in lesions that are at higher risk of restenosis. ${ }^{94}$ Thus, in these slightly more severe lesions, in-stent restenosis was 3\% (significantly less than in control group at 35.4\%, $\mathrm{p}<0.001)$ but the peri-stent restenosis rate was $9 \%$ suggesting that the drug had not controlled balloon injury at the edges. The reason for balloon injury at the margins is unclear but may be to do with balloon overhang or the technique of pulling the balloon back into the stent after deployment and reinflating it (something that has not been standard practice in Europe with the availability of more compliant stents). Clinical outcomes in SIRIUS were very encouraging; target vessel failure (MACE plus target lesion revascularisation (TLR)) fell from $21.0 \%$ to $8.6 \%(\mathrm{p}<0.001)$ driven by a reduction in TLR (from $16.6 \%$ to $4.1 \%$ ). The E-SIRIUS trial was a European study of sirolimus eluting stents testing patients at a still higher risk than those in SIRIUS. Care about technique and the use of direct stenting in $28 \%$ of patients appears to have abolished the so called edge effect. Thus, while the in-stent restenosis rate was 3\% as in SIRIUS the in-segment stenosis was contained at $5 \% .{ }^{95}$ The "New SIRIUS" data (that is, the combination of E-SIRIUS and C-SIRIUS) have set the new standard for sirolimus eluting stents with a low in-stent restenosis rate and a low incidence of clinical events (TLR at nine months $4 \%$ ).

Certain groups of patients have a higher risk of restenosis; thus, patients with diabetes and those with a small reference vessel diameter in particular have been reported to have restenosis rates of up to $40 \%$, especially if both factors are present. In the RAVEL trial the late loss for all control patients was $0.8 \mathrm{~mm}$ and that for all those treated was $-0.01 \mathrm{~mm}$, whereas in the diabetic subgroup the control late loss was $0.82 \mathrm{~mm}$ and $0.08 \mathrm{~mm}$ in those treated with a sirolimus stent. The restenosis rate remained at $0 \%$ even in vessels with reference diameters of $2.05 \mathrm{~mm}$, whereas the control group patients with a reference vessel of this diameter had a restenosis rate of $37 \%$. In the New SIRIUS (combined) data the nondiabetic control TLR rate fell from $18.3 \%$ to $3.3 \%$ in treated patients, whereas in diabetic patients the TLR rate fell $25.0 \%$ in diabetic controls to $6.7 \%$ in diabetic sirolimus treated patients.

The current (in 2005) competitor to rapamycin is paclitaxel. This drug acts further down the smooth muscle cell cycle just before cell division. There have been a number of studies through the ELUTES and TAXUS programmes. In the ELUTES study with drug applied directly to the stent, angiographic restenosis was reduced from $21 \%$ to $3 \%$ at a dose density of $2.7 \mu \mathrm{g} / \mathrm{mm}$ stent with late loss falling from $0.73 \mathrm{~mm}$ to $0.1 \mathrm{~mm} .{ }^{96}$ These results were mirrored in the Asia Pacific trial of a different stent but with the same loading conditions and dose regimen (the ASPECT trial). IVUS in this study showed that effects were due to a reduction in in-stent tissue growth rather than to any adverse effects on positive remodelling. ${ }^{97}$ For the RAVEL and the ELUTES trial clopidogrel was given for two and three months, respectively, to cover potential adverse effects on endothelium. There were no excess stent thromboses in either study. In the SCORE trial paclitaxel was loaded on to an unconventional stent in excessive doses $(2000 \mu \mathrm{g} v$ maximum $90 \mu \mathrm{g}$ for TAXUS and ELUTES, respectively) and not surprisingly there were excess stent thromboses and excess late restenosis. The paclitaxelnon-polymer stent combination has been shown not to be effective in the DELIVER-1 trial, almost certainly due to inadequate loading of paclitaxel on to the stent used for the DELIVER programme (about $15 \mu \mathrm{g} / \mathrm{mm}^{2}$ as opposed to $3.0 \mu \mathrm{g} / \mathrm{mm}^{2}$ in ELUTES and $3.1 \mu \mathrm{g} / \mathrm{mm}^{2}$ in ASPECT. ${ }^{96} 97$

In the TAXUS study series a polymer is used to load the drug on to the stent. In the TAXUS I study biological efficacy was noted with a reduction in late loss from $0.71 \mathrm{~mm}$ to $0.36 \mathrm{~mm}$. Further trials (TAXUS II-VI) exploring the value of paclitaxel in lesions at higher risk of restenosis are ongoing. These studies have shown that paclitaxel applied with a polymer to a stent has significant effects on outcome after stenting. Thus, in the TAXUS II trial (equivalent to the sirolimus SIRIUS study) 536 patients were randomly 
allocated in double blind fashion to either slow (SR) or moderate drug release (MR) formulations and compared with controls. The formulations did not differ and both were significantly better than control; at six months, percentage net volume obstruction within the stent was significantly lower for TAXUS stents (7.9\% SR and $7.8 \% \mathrm{MR}$ ) than for respective controls $(23.2 \%$ and $20.5 \%, \mathrm{p}<0.0001$ for both). This corresponded with a reduction in angiographic restenosis from $17.9 \%$ to $2.3 \%$ in the SR cohort $(\mathrm{p}<0.0001)$ and from $20.2 \%$ to $4.7 \%$ in the MR cohort ( $\mathrm{p}=0.0002$ ). Clinical outcome was improved, driven by TLR: MACE at 12 months was significantly lower $(p=0.0192)$ in the TAXUSSR $(10.9 \%)$ and TAXUS-MR $(9.9 \%)$ groups than in controls (22.0\% and $21.4 \%$, respectively).$^{98}$

Recently the TAXUS IV data have been published..$^{99}$ This study has also shown the efficacy of this stent-drug combination but in higher risk lesions and, more important, benefit has been shown in both diabetic patients and patients with small vessel stents (TLR: vessel size $>3.0 \mathrm{~mm}, 2.5 \%$ and size $<2.5 \mathrm{~mm}, 3.4 \%$; in New Sirius, mean vessel size was $2.56 \mathrm{~mm}$ and TLR $3.6 \%$, diabetics $23.2 \%$; and in TAXUS IV, TLR in patients without diabetes, $2.4 \%$, patients taking oral antidiabetes medication, $4.8 \%$, and patients with insulin dependent diabetes, 5.9\%). We await the results of TAXUS VI, a study of very long and small vessels.

In the DELIVER-2 registry (paclitaxel coated stent with no polymer) acceptable rates of restenosis were obtained with paclitaxel eluting stents in lesions longer than $25 \mathrm{~mm}$ (12\%) and in patients with multivessel disease, diabetes, and existing in-stent restenosis (TLR $11.2 \%$, chronic total occlusion $9.5 \%$, and bifurcation $7.6 \%$ ).

In 2005 the pivotal results of two new drug-stent combination trials will be available: ENDEAVOR II will test a Medtronic driver stent coated with ABT 578, and the FUTURE studies will report on a Guidant stent coated with everolimus. Both agents, which are sirolimus analogues, have been shown in small pilot studies to be potentially as effective as available drug-stent combinations.

The benefit of drug eluting stents is through a robust effect on tissue growth in simple and moderately complex clinical scenarios; they appear to be of benefit in all patients. However, even with these drug eluting stents in-stent restenosis appears not to have been abolished and what we do for such patients (in-stent restenosis in drug eluting stents) is under review. NICE approved drug eluting stents in 2003 for specific subgroups-long lesions $(>15 \mathrm{~mm})$ and small vessels $(<3 \mathrm{~mm}$ diameter $)$-allowing for drug eluting stent use to be artery specific rather than patient specific (that is, $>1$ stent per patient if indicated). Diabetic patients were not included, since the adjudication was before completion of TAXUS IV and so diabetics should be included in the next NICE review due in 2006. The reality is, however, that drug eluting stents in the UK may be used in only between $35 \%$ and $60 \%$ of patients because of concerns over cost effectiveness; in any event it may take some time to reach these levels of use and therefore some time to have any real impact on in-stent restenosis.

The use of drug eluting stents for in-stent restenosis has been tested in a few small studies with mixed results (poor results with TAXUS III and in the Rotterdam experience, for example). Two trials, SISR (sirolimus stent versus vascular brachytherapy) and the TAXUS V substudy (TAXUS stent versus vascular brachytherapy), should provide data as to the value of drug eluting stents for in-stent restenosis in early 2006. There is a very effective treatment for in-stent restenosis, namely vascular brachytherapy.

\section{Vascular brachytherapy}

Effective treatment in the form of vascular brachytherapy is available, although there is evidence that there is a late catch up phenomenon after initially successful treatment. In-stent re-restenosis rates are reduced by about $60 \%$ and the clinical (target vessel revascularisation) rates by about $50 \%$ irrespective of whether local radiation is delivered as a $\beta$ emitter or as a $\gamma$ emitter. The START and INHIBIT trials specifically showed that compared with placebo the use of strontium90/yttrium and phosphorus-32 radionuclide, respectively, after re-ballooning to deliver 16 Gy at $2 \mathrm{~mm}$ inside the vessel wall reduced in-stent recurrence from $42.2 \%$ to $14.2 \%$ $(\mathrm{p}<0.001)$ and $48 \%$ to $16 \%(\mathrm{p}<0.0001)$, respectively. ${ }^{100}{ }^{101}$ Vascular brachytherapy appears less beneficial when used as a primary treatment in non-stented vessels. Many aspects of the BETACATH trial are likely to have seriously influenced the negative result of this study, such as geographic miss. ${ }^{102}$ The RENO registry of over 1000 patients confirmed the value of vascular brachytherapy for in-stent restenosis in the real world with a MACE rate of $17.7 \%$, very similar to that in all the randomised trials. ${ }^{103}$ The RENO group have produced several publications assessing vascular brachytherapy with a $\beta$ emitter in various subsets of patients such as those with chronic total occlusions and in-stent restenosis in vein grafts. With more than 45000 procedures performed in the USA by 2003, reports of overall MACE rates of 3.8\% justify the value of this procedure in in-stent restenosis. Late benefit (up to five years) has now been shown in the original SCRIPPS $\gamma$ emitting study. ${ }^{104}$ At five years' follow up, TLR was significantly lower in the iridium-192 group $(23.1 \% v$ $48.3 \%, \mathrm{p}=0.05)$; the five year event-free survival rate (freedom from death, MI, or TLR) was greater in the ${ }^{192} \mathrm{Ir}$ treated patients $(61.5 \% \vee 34.5 \%, \mathrm{p}=0.02)$.

The challenge for the foreseeable future is to assess the benefit of drug eluting stents in groups of patients at increased risk of restenosis, to ensure their clinical uptake accordingly, and to deal with the residual prevalence and new incidence of in-stent restenosis appropriately. Further stenting with a drug eluting stent may be the best way to deal with in-stent restenosis; treatment of those patients who have received a drug eluting stent for the first time who then develop in-stent restenosis will prove a challenge, although many such patients appear to have in-stent restenosis as a focal recurrence allowing perhaps for treatment with a balloon alone.

\section{Small vessel disease}

There is no doubt that small vessel disease carries a higher risk of adverse clinical outcome. In addition to higher restenosis rates stent thrombosis is more likely the lower the stent to vessel wall ratio. It is true that stenting is a better option than balloon alone; thus, the BESMART study $(\mathrm{n}=381)$ observed a restenosis rate of $22.7 \%$ in the stent group versus $48.8 \%$ in balloon group $(p<0.0001)$ and a TLR rate of $13 \%$ versus $25 \%$, respectively $(p<0.016) .{ }^{105}$ The ISAR-SMART trial, however, showed no benefit from small vessel stenting $(35.7 \% \vee 37.4 \%$ with a vessel size of $2.0-$ $2.8 \mathrm{~mm}) .{ }^{106}$ The one year follow up of the SISCA trial of heparin coated stents has been published; at six months the clinical outcome was significantly better in the stent group than in the PTCA group, with an event-free survival in $90.5 \%$ and $76.1 \%$, respectively ( $p=0.016$ ). From six to 12 months, event-free survival was unchanged in both groups, showing a sustained long term clinical benefit of elective stenting. ${ }^{107}$ Drug eluting stents in such high risk patients appears to influence beneficially the natural history of small vessel disease stenting. The severity of the problem is exaggerated in diabetic patients with small reference diameters. In a subgroup of the ISAR-SMART trial angiographic restenosis occurred in $44 \%$ of the patients who received a stent and in $45 \%$ of the PTCA patients $(p=0.90)$. Target vessel revascularisation was needed in $13(25 \%)$ of the stent 
patients and $10(20 \%)$ of the PTCA patients $(p=0.55)$. During the one year follow up, five $(10 \%)$ of the stented patients died or incurred MI compared with three $(6 \%)$ of the PTCA patients $(\mathrm{p}=0.50){ }^{108}$

The treatment of small vessel disease by PCI remains a challenge. It is clear that physicians may not wish to exclude patients from the potential benefit of stenting based on vessel size alone and this group of patients is likely to benefit from newer innovations including novel stent designs. As smaller vessels are stented, perhaps with the "security" of drug eluting stents reducing restenosis, the potential re-emergence of stent thrombosis will need to be monitored.

\section{LMS stenting}

PCI on unprotected LMS disease has been regarded as inappropriate, and NICE implied that surgery was the desired option. However, several groups worldwide are, through the use of registries, identifying the real overall risks of PCI and highlighting the patients in whom such an intervention would be acceptable. Early studies such as that by Park et al ${ }^{109}$ suggested excellent results in patients he regarded as low risk ( $100 \%$ success rate, $17 \%$ clinical recurrence at six months, and only one death).

Ellis et $a l^{110}$ reported on the ULTIMA registry of 279 consecutive patients who had LMS PCI at 25 centres between 1993 and 1998. The outcome appeared to depend on patient characteristics. Forty six per cent of these patients were deemed inoperable or at high surgical risk. Overall $13.7 \%$ died in hospital, and the rest were followed up for a mean of 19 months. The one year all cause mortality was $24.2 \%$, with a cardiac mortality of $20.2 \%$, the acute MI rate was $9.8 \%$, and $9.4 \%$ needed CABG. Independent correlates of all cause mortality were left ventricular ejection fraction $\leqslant 30 \%$, mitral regurgitation grade 3 or 4 , presentation with acute MI and shock, creatinine $\geqslant 177 \mu \mathrm{mol} / \mathrm{l}$, and severe lesion calcification. Among the $32 \%$ of patients $<65$ years old, with left ventricular ejection fraction $>30 \%$ and without shock, none died during the procedure and the one year mortality was only $3.4 \%$. It is clear that outcome is dependent on patient characteristics. Thus, in the study of Black et al, ${ }^{111}$ mortality to 1000 days after the intervention was 20.5\% among patients who were deemed unsuitable for surgery compared with $3.8 \%$ among those for whom surgery was an option. The non-surgical patients had a worse mean ejection fraction. More recent published reports include a registry by Brueren et al, ${ }^{112}$ who suggested that the considerations regarding treatment for LMS (albeit non-bifurcating LMS) be directed towards PCI.

Kelley et al $^{113}$ feel less inclined towards LMS PCI, showing that patients with unprotected LMS have worse outcomes than do those with protected LMS, as might be expected. At one year, survival was reduced in the unprotected group (72\% $v 95 \%, \mathrm{p}<0.001)$ and MACE was increased in the unprotected patients ( $49 \% \vee 25 \%, \mathrm{p}=0.005)$.

Who should undergo unprotected LMS PCI? Certainly those who are rejected for surgery and who are disabled by angina can be considered after a full and frank discussion with patient and family. In young patients with ideal anatomy LMS PCI can also be considered. Ostial or short LMS disease is high risk if the artery is calcified; rotational atherectomy may be considered appropriate in these patients or in those with bifurcation disease; bifurcation anatomy also confers a higher risk because of acute stent thrombosis. Data suggest that patients with further multivessel disease or reduced ejection fraction are more likely to have MACE. One group have found that anatomy did not influence event-free survival but that age $<65$ years, normal left ventricular ejection fraction, and absence of intra-aortic balloon pump use did. ${ }^{114}$ Anything less than a perfect PCI result (some considered this to be judged by the use of IVUS) is unacceptable.

The SYNTAX trial will enrol patients with three vessel disease, with and without LMS lesions, treated by a drug eluting stent (TAXUS) or surgical revascularisation and will provide important outcome and cost effectiveness data on an unselected group of patients.

\section{Bifurcation lesions}

The best approach to bifurcation disease remains unresolved. Some interventionists question whether PCI is the treatment of choice because of the technical problems and high incidence of acute and chronic events. Stent deployment in both arms of the bifurcation or the stenting of one and ballooning of the other depending on the presence of disease or result of intervention are current topics for debate. Most operators leave the side branch depending on the presence or absence of disease, side branch size, and provisional result. Whereas some authors have reported very high restenosis rates, Lefevre et al ${ }^{115}$ reported MACE rates of between $17.1 \%$ and $29.2 \%$, which according to their data were in part influenced by the experience of the operator. The use of so called kissing balloons appeared to influence outcome beneficially. Others have shown that stenting of the side branch may not be essential but choosing which to stent and which to leave is the subject of several proposed studies. Bifurcation stenting is less enthusiastically undertaken but may re-emerge with the advent of drug eluting stents, although it is clear that if there is a residual untreated triangle between the main vessel and the side branch this is likely to be the site of restenosis even with drug eluting stents. Such areas of in-stent restenosis are easily treated with vascular brachytherapy. ${ }^{116}$ Recent changes in techniques such as modified T, crush, or modified crush stenting have improved the immediate outcome compared with culotte or Y stenting, although there are few long term outcome data. ${ }^{17}$ Use of drug eluting stents with such techniques does raise concerns about the amount of drug delivered to the vessel wall because of overlapping stents. A true bifurcation stent that can be effectively, completely, and reliably coated with antiproliferative drug is eagerly awaited, although early designs are available. ${ }^{118}$

\section{Stents versus surgery}

Several randomised studies have compared stenting with surgery for multivessel disease (ARTS trial, SOS trial). The one year results of the ARTS trial $(n=1200)$, which compared stenting (2.7 (0.2) stents per patient) with surgery (2.8 (1.1) anastomoses per patient) in multivessel disease have been published. ${ }^{119}$ The event-free survival rate was higher in the surgical patients $(87.3 \% v 73.3 \%)$ entirely due to the need for reintervention in the stented patients. An ongoing study (ARTS-2) is addressing this issue with the use of drug eluting stents; unfortunately this is a registry only. The ERACI-II study appeared to show early 30 day benefit of stenting over coronary surgery (hazard ratio for death 0.38 , $95 \%$ CI 0.17 to 0.84 ), although this was a small study and the groups appeared to be equal at one year. ${ }^{120}$ The UK based SOS trial has been completed and the results clearly show that even in the era of stenting early outcome after coronary surgery is better than after PCI when the need for revascularisation is the end point ( $17 \%$ PCI $v 4 \%$ surgery at one year, $\mathrm{p}<0.001)$. Any mortality benefit from surgery is driven by non-cardiac (cancer) deaths. ${ }^{121}$

In a study from the Rotterdam group, 755 patients with stable angina were randomly assigned to coronary stenting $(\mathrm{n}=374)$ or bypass surgery $(\mathrm{n}=381)$, and 450 patients with unstable angina were randomly assigned to coronary stenting $(n=226)$ or bypass surgery $(n=224) .{ }^{122}$ This 
study confirms equivalence in terms of death, acute MI, and cerebrovascular accident between stenting and surgery for multivessel disease in both stable and unstable patient groups $(91.2 \% \vee 88.9 \%)$ and in stable patients $(90.4 \% v$ $92.6 \%)$, respectively. Again, surgical patients had less need for revascularisation, and freedom from repeat revascularisation at one year was significantly lower in both unstable and stable patients treated with stenting (needed in $16.8 \%$ and $16.9 \%$, respectively) compared with bypass surgery (needed in $3.6 \%$ and $3.5 \%$, respectively). Many of the differences between stenting and surgery relate to the need for repeat revascularisation, an event that should be significantly decreased with drug eluting stents. The optimum revascularisation strategy for the treatment of diabetic patients remains unclear.

Hybrid procedures combining left internal mammary artery grafting with PCI to any remaining diseased vessels has been reported and is now a generally accepted strategy. ${ }^{123}$ The data from Reiss et al ${ }^{124}$ suggest that this can be a rational approach especially since cardiopulmonary bypass can be avoided. Restenosis in the angioplastied vessels (eight of 34 repeat angiograms) is likely to be avoided by the use of drug eluting stents.

Comparisons between angioplasty plus stenting and minimally invasive surgery to the left anterior descending artery are under way (the AMIST study). Recruitment is slow for a number of logistical reasons and to date 88 patients have been randomly allocated to treatment. Meanwhile a small study has been published; 101 patients with high grade stenosis affecting the proximal left anterior descending artery were randomly assigned to minimally invasive surgery or stenting. ${ }^{125}$ At six months, quantitative coronary angiography showed an anastomotic stenosis rate of $4 \%$ after surgical intervention and a restenosis rate of $29 \%$ after stenting $(p<0.001)$. There were no significant differences in MACE or cerebral events, need for repeat target vessel revascularisation, return of angina pectoris, physical work capacity, or use of antianginal drugs between the two groups.

\section{Cardiogenic shock}

Cardiogenic shock carries a high mortality. Shaw et al l $^{126}$ published data in 2002 from the 1998-2000 ACC-National Cardiovascular Data Registry (ACC-NCDR); data on 100253 PCI procedures were collected at the ACC-NCDR. Factors associated with increased risk of PCI mortality (with odds ratios in parentheses) were cardiogenic shock (8.49); increasing age (2.61 to 11.25); salvage (13.38), urgent (1.78), or emergent procedure (5.75); need for preprocedural intra-aortic balloon pump insertion (1.68); decreasing left ventricular ejection fraction (0.87 to 3.93); and presentation with acute MI (1.31), diabetes (1.41), renal failure (3.04), and chronic lung disease (1.33). Interestingly the use of nonstent devices was associated with an increased risk (1.64).

Even when current best practice is used, medium term outcome in cardiogenic shock is poor. During 2.5 years of follow up, the mortality rates for stent plus abciximab, stent only, PTCA plus abciximab, and PTCA alone were 33\%, 43\%, $61 \%$, and $68 \%$, respectively (log rank $\mathrm{p}=0.028$ ). ${ }^{127}$ Despite data from registries suggesting a benefit from intervention, the only randomised trial completed has failed to show benefit. In the SHOCK trial patients presenting with cardiogenic shock were randomly assigned to emergency revascularisation (152 patients) or initial medical stabilisation ( 150 patients). ${ }^{128}$ Revascularisation was accomplished by either CABG or angioplasty. Overall mortality at 30 days did not differ significantly between the revascularisation and medical treatment groups $(46.7 \% \vee 56.0 \%$, for a difference of $-9.3 \%, 95 \%$ CI $-20.5 \%$ to $1.9 \%, p=0.11)$. Six month mortality was lower in the revascularisation group than in the medical treatment group $(50.3 \% v 63.1 \%, \mathrm{p}=0.027)$. There are two interesting aspects to this study. Firstly, intraaortic balloon counterpulsation was used in $86 \%$ of the patients in both groups; and secondly, the study was undertaken (over a longish period) before the increased uptake of glycoprotein IIb/IIIa receptor blockers.

In general, intervention continues to be clinically considered for patients with cardiogenic shock because the mortality is so high. Patients who can benefit have been recently highlighted in a further analysis of the SHOCK trial: overall one year mortality in PCI patients was 50\% and was $39 \%$ if PCI was successful but $85 \%$ if unsuccessful $(\mathrm{p}<0.001)$; if TIMI grade III flow was achieved, the mortality was $38 \%$ but $55 \%$ with TIMI grade II flow and $100 \%$ with TIMI grade $0-\mathrm{I}$ flow $(\mathrm{p}<0.001)$. Mortality was $67 \%$ if severe mitral regurgitation was documented. Independent correlates of mortality were increasing age $(p<0.001)$, lower systolic blood pressure $(p=0.009)$, increasing time from random allocation to PCI $(\mathrm{p}=0.019)$, lower post-PCI TIMI flow $(0-\mathrm{I} \quad v$ II-III, $\mathrm{p}<0.001)$, and multivessel PCI $(\mathrm{p}=0.040) .{ }^{129}$ Further increased use of intra-aortic balloon pumps in the nonintervention centre and early transfer may have an important bearing on patients whose prognosis is alterable. Determining who these patients are is difficult.

\section{Chronic total occlusions}

Increasingly, patients with chronic total occlusions will make up the largest proportion of patients referred for surgery, especially those with unfavourable anatomy such as those with no stump or antegrade collaterals. Successful treatment of chronic total occlusions, while improved with the advent of polymer coated wires and low profile balloons, remains less predictable. It is one of the remaining angiographic presentations where coronary surgery is still commonly needed, since successful recanalisation of chronic total occlusion is quoted at between $65 \%$ and $75 \%$. In a review by Puma et al ${ }^{130}$ successful recanalisation was achieved in $65 \%$ of patients, with inability to cross with the wire being the most common cause of failure. Angina status improves with a successful procedure (70\% compared with $31 \%$ with a failed procedure) with subsequent referral for surgery evidently less common (3\%). While patients initially do better if the chronic total occlusion can be treated, high restenosis rates lead to a greater need for repeat procedure in these patients compared with those in whom success was not achieved and who have survived without need for CABG. ${ }^{131}$ While drug eluting stents may improve this outcome, they will not contribute to primary success rates. A review of 2007 patients treated between 1980 and 1999 has shown increasing technical success with an overall rate reported at $74.4 \%$ with a slope of $1.0 \% /$ year $(p=0.02)$. Successful treatment of chronic total occlusion conferred a distinct 10 year survival advantage over failed treatment $(73.5 \% \quad v \quad 65.1 \%, \quad \mathrm{p}=0.001) .{ }^{132}$ Stent deployment, if the vessel can be opened, has been shown to improve outcome. ${ }^{133} 134$ Thus, successfully reopening and stenting a chronic total occlusion appears to have significant clinical benefits. Not all vessels can be opened, however, and in such patients novel alternative strategies may, if shown to be successful, improve overall clinical outcome.

Several lesion factors predict interventional failure. ${ }^{135-137}$ One study prospectively analysed 957 consecutive coronary interventions in 1404 stenoses and found that irregular contour $(p=0.0001)$, calcification $(p=0.0076)$, eccentric anatomy $(\mathrm{p}=0.0001)$, thrombus $(\mathrm{p}=0.0001)$, and chronicity ( $p=0.001)$ were associated with less success. The presence of antegrade collaterals is often regarded as an important factor indicating both the duration of the occlusion and the likelihood of failure. In one study 397 patients were 
divided into two groups: group I had chronic total occlusions with bridging collateral vessels (97 patients, 109 total occlusions), and patients in group II had chronic total occlusions without such vessels (300 patients, 324 total occlusions). ${ }^{138}$ Angioplasty for single vessel disease was performed less in patients in group I than in group II $(22 \%$ $v 36 \%, \mathrm{p}<0.05$, power value 0.77 ) indicating operator selection against a background understanding of likelihood of success. It is not surprising that in this study there was only a trend towards a reduction in likelihood of success in those with antegrade collaterals. Procedural success was achieved in 82 chronic total occlusions in group I and 270 chronic total occlusions in group II $(75 \% v 83 \%, \mathrm{p}=0.07$, power value 0.53 ). The rates of restenosis and reocclusion were $54 \%$ and $16 \%$, respectively, for group I $(p=0.76$, power value 0.51 ) and $56 \%$ and $13 \%$, respectively, for group II $(\mathrm{p}=0.46$, power value 0.47$)$. While these data showed a trend to reduced success with bridging collaterals, others have clearly shown a significant adverse effect. Tan et al ${ }^{139}$ published a stepwise logistic regression analysis for predicting PCI success in patients with chronic total occlusion and identified the presence of bridging collaterals $(p<0.001)$, the absence of a tapered entry configuration $(p<0.001)$, estimated duration of occlusion of $>3$ months $(p=0.001)$, and a vessel diameter of $<3 \mathrm{~mm}(\mathrm{p}=0.003)$ as independent predictors of procedural failure.

One observational study was published in 2003; in the TOAST-GISE study of 390 chronic total occlusions procedural success was obtained in $73 \%$ of lesions. ${ }^{140}$ In-hospital MACE occurred in $5.1 \%$ of patients. Multivariate analysis identified chronic total occlusion length $>15 \mathrm{~mm}$ or not measurable, moderate to severe calcifications, duration $\geqslant 180$ days, and multivessel disease as significant predictors of PCI failure. At 12 months, patients with a successful procedure experienced a lower incidence of cardiac deaths or MI (1.05\% $v 7.23 \%$, $\mathrm{p}=0.005)$, a reduced need for CABG $(2.45 \% \vee 15.7 \%$, $\mathrm{p}<0.0001)$, and greater freedom from angina $(88.7 \% \mathrm{v}$ $75.0 \%, \mathrm{p}=0.008$ ) compared with patients who had an unsuccessful procedure.

Various new technologies have evolved in an attempt at improving success including guided wire systems, with which success rates of $60 \%$ are reported in patients with previous routine wire failure by using optical coherence reflectometry. ${ }^{141}$ This device uses red light laser to distinguish a normal vessel wall, at which point the device fails to deliver low wattage energy. Laser wires, nibbling devices, and robotic steering are alternative treatment options being evaluated. ${ }^{142}$ Some researchers have attempted in preclinical models to dissolve the clot with collagenase. Successful guidewire crossings were significantly higher in collagenase treated arteries (13 of $21(62 \%))$ than in placebo treated arteries (seven of $24(29 \%), p=0.028)$. Others are working on drug eluting stents that release growth factors such as vascular endothelial growth factor and fibroblast growth factor 2 that will be placed at the origin of the chronic total occlusion with no attempt to open it, but merely to allow the stent released drug to enhance antegrade collaterals. If the antegrade collateral supply can be increased then intervention (PCI or surgery) may not be required.

\section{Summary}

PCI has been subject to may studies, which have helped define improvements in clinical practice. Consequently the procedure has become more efficacious and safer. Further progress based on appropriate preclinical and clinical trials should enable clinicians to extend PCI to additional groups of patients. Areas needing scientific scrutiny have been defined.

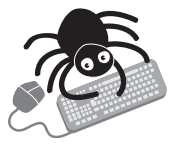

Appendices (appendix 1, BCIS dataset; appendix 2, BCIS database, and appendix 3, BCIS peer review visit (Pro-forma)) appear on the Heart website$\mathrm{http}: / /$ www.heartinl.com/supplemental and at http://www.cardiology.co.uk/bcis/bcis_dataset_v5.1.3.xls, http://www.cardiology.co.uk/bcis/ pci_db_10.0/bcis_10.0.zip, and http://www.cardiology.co.uk/bcis/pcisites2_2.pdf, respectively.

\section{Authors' affiliations}

K D Dawkins, T Gershlick, A Chauhan, D Smith, British Cardiovascular Intervention Society, London, UK

M de Belder, P Schofield, J Watkins, H H Gray, British Cardiac Society, London, UK

G Venn, St Thomas' Hospital, London, UK

Correspondence to: Dr Keith D Dawkins, Wessex Cardiac Unit, Southampton University Hospital, Southampton SO16 6YD, UK; keith@ dawkins.org

Accepted 27 October 2005

\section{REFERENCES}

1 Parker DJ, Gray HH, Balcon R, et al. Planning for coronary angioplasty: guidelines for training and continuing competence. Heart 1996;75:419-25.

2 Coronary angioplasty: guidelines for good practice and training. Joint Working Group on coronary angioplasty of the British Cardiac Society and British Cardiovascular Intervention Society. Heart 2000;83:224-35.

3 Department of Health. Payment by results consultation: preparing for 2005. London: Department of Health, 2003, www.dh.gov.uk/assetRoot/04/06/ 53/24/04065324.pdf (accessed 1 Nov 2005).

4 British Cardiovascular Intervention Society. www.bcis.org.uk (accessed 1 Nov 2005).

5 Gruentzig AR, Myler RK, Stertzer H, et al. Coronary percutaneous transluminal angioplasty: preliminary results. Circulation 1978;586/suppl II):56.

6 NICE. Guidance on the use of coronary artery stents, Technology appraisal no 71. London: National Institute for Clinical Excellence, 2003, www.nice.org.uk/pdf/TA71_coronaryarterystents_fullguidance.pdf (accessed 1 Nov 2005)

7 Gray HH, Callum KG. Death following coronary angioplasty [editorial]. Heart 2002;87:185-6.

8 Department of Health. National Service Framework for Coronary Heart Disease. London: Department of Health, 2000, www.dh.gov.uk/assetRoot/ 04/01/91/20/04019120.pdf (accessed 1 Nov 2005).

9 European Society of Cardiology, American College of Cardiology. Myocardial infarction redefined: a consensus document of the Joint European Society of Cardiology/American College of Cardiology Committee for the Redefinition of Myocardial Infarction. J Am Coll Cardiol 2000;36:959-69.

10 British Cardiac Society, Royal College of Physicians. Guideline for the management of patients with acute coronary syndromes without persistent ECG ST segment elevation. British Cardiac Society Guidelines and Medical Practice Committee, and Royal College of Physicians Clinical Effectiveness and Evaluation Unit. Heart 2001;85:133-42.

11 Bertrand ME, Simoons ML, Fox KAA, et al. Management of acute coronary syndromes: acute coronary syndromes without persistent ST segment elevation. Recommendations of the Task Force of the European Society of Cardiology. Eur Heart J 2000;21:1406-32.

12 ACC/AHA guidelines for percutaneous coronary intervention (revision of the 1993 PTCA guidelines). A report of the American College of Cardiology/ American Heart Association Task Force on Practice Guidelines (Committee to Revise the 1993 Guidelines for Percutaneous Transluminal Coronary angioplasty). Endorsed by the Society for Cardiac Angiography and Interventions. J Am Coll Cardiol 2001;37:2239, i-xvi.

13 European Society of Cardiology. Guidelines for percutaneous coronary interventions. The Task Force for Percutaneous Coronary Interventions of the European Society of Cardiology. Eur Heart J 2005;26:804-47.

14 www.hpa.org.uk/radiation/ (accessed 1 Nov 2005).

15 De Belder MA, on behalf of the Council of the British Cardiovascular Intervention Society. Cardiac intervention procedure in the United Kingdom 1997: developments in data collection. Heart 1999;82(suppl II):II2-9.

16 NICE. Guidance on the use of glycoprotein Illb/llla inhibitors in the treatment of acute coronary syndromes. Technology appraisal guidance no 12. London: National Institute for Clinical Excellence, 2000, www.nice.org.uk/ $\mathrm{pdf} /$ Nice+GLYCOPROTEIN+12+guidan.pdf (accessed 1 Nov 2005)

17 NICE. Guidance on coronary artery stents in the treatment of ischaemic heart disease. Technology appraisal guidance no 4. London: National Institute for Clinical Excellence, 2000

18 GMC. Good medical practice, 3rd edn. London: General Medical Council 2001. 
19 Seeking patients' consent: the ethical considerations. General Medical Council, November 1998. www.gmc-uk.org/guidance/library/consent.asp (accessed 1 Nov 2005).

20 Department of Health. Good practice in consent implementation guide: consent to examination or treatment. London: Department of Health, 2001, www.dh.gov.uk/assetRoot/04/01/90/61/04019061.pdf (accessed 1 Nov 2005).

21 Human Rights Act 1998. www.hmso.gov.uk/acts/acts 1998/19980042.htm (accessed 1 Nov 2005).

22 Department of Health. The NHS plan: a plan for investment, a plan for reform. London: Department of Health, 2000, www.dh.gov.uk/assetRoot/ 04/05/57/83/04055783.pdf (accessed 1 Nov 2005).

23 Department of Health. Winning the war on heart disease: progress report 2004. London: Department of Health, 2004, www.dh.gov.uk/assetRoot/ 04/07/71/58/04077158.pdf (accessed 1 Nov 2005).

24 Royal College of Physicians. Implementation of the European Working Time Directive by August 2004 for specialist registrars in acute hospital medicine. College Commentary suppl no 1. London: Royal College of Physicians, 2003 www.rcplondon.ac.uk/pubs/books/EWTD/ewtd_supplement.pdf (accessed 1 Nov 2005).

25 Hackett D, on behalf of the Cardiac Workforce Planning Group, British Cardiac Society. Cardiac workforce requirements in the UK, 2004. www.bcs.com/cgi-bin/ library.cgi ?action $=$ detail\&id $=221 \&$ dir_publisher_varid $=6$.

26 Foley DP, Serruys PW. Restenosis after percutaneous interventions: the evolving angiographic perspective. Coron Artery Dis 1993:4:1129-36.

27 Serruys PW, de Jaegere P, Kiemeneij F, et al. A comparison of balloonexpandable-stent implantation with balloon angioplasty in patients with coronary artery disease. Benestent Study Group. N Engl J Med 1994;331:489-95.

28 Fischman DL, Leon MB, Baim DS, et al. A randomised comparison of coronary stent placement and balloon angioplasty in the treatment of coronary artery disease. Stent restenosis study investigators. N Engl J Med 1994;331:496-501.

29 Kimura T, Abe K, Shizuta S, et al. Long-term clinical and angiographic follow-up after coronary stent placement in native coronary arteries. Circulation 2002; 105:2986-91.

30 Maynard C, Every NR, Chapko MK, et al. Improved outcomes associated with stenting in the healthcare cost and utilization project. J Interv Cardiol 2001;14:159-63.

31 Louvard Y, Lefevre T, Allain A, et al. Coronary angiography through the radial or the femoral approach: The CARAFE study. Catheter Cardiovasc Interv 2001;52:181-7.

32 Sandborg M, Fransson SG. Pettersson H. Evaluation of patient-absorbed doses during coronary angiography and intervention by femoral and radial artery access. Eur Radiol 2003;14:653-8.

33 Ziakas AA, Klinke BP, Mildenberger CR. Safety of same-day discharge radial percutaneous coronary intervention: a retrospective study. Am Heart J 2003; 146:699-704

34 Kimmel SE, Saver WH, Brensinger C. Relationship between coronary angioplasty laboratory volume and outcomes after hospital discharge. Am Heart J 2002; 143:833-40.

35 Magid DJ, Calonge BN, Rumsfeld JS, et al. Relation between hospital primary angioplasty volume and mortality for patients with acute $\mathrm{Ml}$ treated with primary angioplasty vs thrombolytic therapy. JAMA 2000;284:3131-8.

36 Hamon M, Richardeau $Y$, Lecluse $E$, et al. Direct coronary stenting without balloon predilation in acute coronary syndromes. Am Heart $J$ 1999;138:55-8.

37 Martinez-Elbal L, Ruiz-Nodar JM, Zueco J. Direct coronary stenting versus stenting with balloon pre-dilation: immediate and follow-up results of a multicentre, prospective, randomized study. The DISCO trial. Eur Heart $J$ 2002;23:633-40.

38 Atmaca Y, Altin T, Ozdol Sadi C, et al. Direct stent implantation in acute coronary syndrome. J Invasive Cardiol 2002;14:308-12.

39 Brito FS Jr, Caixeta AM, Perin MA. Comparison of direct stenting versus stenting with predilation for the treatment of selected coronary narrowings. The DIRECT Study Investigators. Am J Cardiol 2002;89:115-20.

40 IJsselmuiden AJ, Cotton JM. Safe and effective direct implantation of a new stent through $5 \mathrm{~F}$. guiding catheters with delivery from the radial artery: initia results of a prospective registry. Int J Cardiovasc Intervent 2003:5:72-6.

41 Cutlip DE, Leon MB, Ho KK, et al. Acute and nine-month clinical outcomes after "suboptimal" coronary stenting: results from the stent anti-thrombotic regimen study (STARS) registry. J Am Coll Cardiol 1999;34:698-706.

42 Bertrand ME, Rupprecht HJ, Urban P, et al. Double-blind study of the safety of clopidogrel with and without a loading dose in combination with aspirin compared with ticlopidine in combination with aspirin after coronary
stenting: the clopidogrel aspirin stent international cooperative study (CLASSICS). Circulation 2000;102:624-9.

43 Steinhubl SR, Berger PB, Mann JT 3rd. Early and sustained dual oral antiplatelet therapy following percutaneous coronary intervention: a randomized controlled trial. JAMA 2002;288:2411-20.

44 Kastrati A, Mehilli J, Schühlen $\mathrm{H}$, et al. A clinical trial of abciximab in elective percutaneous coronary intervention after pretreatment with clopidogrel. N Engl J Med 2004;305:232-8.

45 Muller I, Besta F, Schulz C. Prevalence of clopidogrel non-responders among patients with stable angina pectoris scheduled for elective coronary stent placement. Thromb Haemost 2003;89:783-7.

46 Neubauer H, Gunesdogan B, Hanefeld C. Lipophilic statins interfere with the inhibitory effects of clopidogrel on platelet function: a flow cytometry study. Eur Heart J 2003;24:1744-9.
47 Saw J, Steinhubl SR, Berger PB. Lack of adverse clopidogrel-atorvastatin clinical interaction from secondary analysis of a randomized, placebocontrolled clopidogrel trial. Circulation 2003;108:921-4.

48 Muller I, Besta F, Schulz C. Effects of statins on platelet inhibition by a high loading dose of clopidogrel. Circulation 2003;108:2195-7.

49 Narins CR, Miller DP, Califf RM, et al. The relationship between periprocedural myocardial infarction and subsequent target vessel revascularization following percutaneous coronary revascularization: insights from the EPIC trial. Evaluation of $\mathrm{Ilb} / \mathrm{Illa}$ platelet receptor antagonist 7E3 in preventing ischemic complications. J Am Coll Cardio 7E3 in preventing

50 EPIC Investigators. Use of a monoclonal antibody directed against the platelet glycoprotein Ilb/Illa receptor in high risk coronary angioplasty. The EPIC investigation. N Engl J Med 1994;330:956-61.

51 The EPISTENT Investigators. Randomised placebo-controlled and balloonangioplasty-controlled trial to assess safety of coronary stenting with use of platelet glycoprotein-Ilb/llla blockade. The EPISTENT investigators. Evaluation of platelet $\mathrm{Ilb} / \mathrm{lll}$ a inhibitor for stenting [see comments]. Lancet 1998;352:87-92

52 Kini A, Kini S, Marmur JD. Incidence and mechanism of creatine kinase-MB enzyme elevation after coronary intervention with different devices. Catheter Cardiovasc Interv 1999:48:123-9.

53 Garbarz E, lung B, Lefevre $G$, et al. Frequency and prognostic value of cardiac troponin I elevation after coronary stenting. Am J Cardio 1999;84:515-8.

54 Bertinchant JP, Polge A, Ledermann B. Relation of minor cardiac troponin I elevation to late cardiac events after uncomplicated elective successful percutaneous transluminal coronary angioplasty for angina pectoris. Am J Cardiol 1999;84:51-7.

55 Topol EJ, Moliterno DJ, Herrmann HC, et al. Comparison of two platelet glycoprotein Ilb/Illa inhibitors, tirofiban and abciximab, for the prevention of ischemic events with percutaneous coronary revascularization. N Engl J Med 2001;344:1888-94

56 Moliterno DJ, Yakubov SJ, DiBattiste PM, et al. Outcomes at 6 months for the direct comparison of tirofiban and abciximab during percutaneous coronary revascularisation with stent placement: the TARGET follow-up study. Lancet 2002;360:355-60

57 Bhatt DL, Marso SP, Lincoff AM. Abciximab reduces mortality in diabetics following percutaneous coronary intervention. J Am Coll Cardiol 2000;35:922-8

58 The ESPRIT Investigators. Novel dosing regimen of eptifibatide in planned coronary stent implantation (ESPRIT): a randomised, placebo-controlled trial. The ESPRIT Investigators. Lancet 2000;356:2037-44.

59 Chan AW, Moliterno DJ, Berger PB. Triple antiplatelet therapy during percutaneous coronary intervention is associated with improved outcomes including one-year survival: results from the do tirofiban and ReoPro give similar efficacy outcome trial (TARGET). J Am Coll Cardiol 2003:42:1188-95.

60 Seybert AL. Bivalirudin administration during percutaneous coronary intervention: emphasis on high-risk patients. Pharmacotherapy 2002;22: 112 S-8S

61 Lincoff AM, Kleiman NS, Kottke-Marchant K. Bivalirudin with planned or provisional abciximab versus low-dose heparin and abciximab during percutaneous coronary revascularization: results of the comparison of abciximab complications with hirulog for ischemic events trial (CACHET). Am Heart J 2002; 143:847-53.

62 Lincoff AM, Bittl JA, Harrington RA. Bivalirudin and provisional glycoprotein $\mathrm{llb} / \mathrm{Illa}$ blockade compared with heparin and planned glycoprotein Ilb/Illa blockade during percutaneous coronary intervention: REPLACE-2 randomized trial. JAMA 2003;28:853-63.

63 Kereiakes DJ, Grines C, Fry E, et al. Enoxaparin and abciximab adjunctive pharmacotherapy during percutaneous coronary intervention. J Invasive Cardiol $2001 ; 13: 272-8$.

64 Ferguson JJ, Antman EM, Bates ER. Combining enoxaparin and glycoprotein $\mathrm{Ilb} / \mathrm{Illa}$ antagonists for the treatment of acute coronary syndromes: final results of the national investigators collaborating on enoxaparin-3 (NICE-3) study. Am Heart J 2003; 146:628-34.

65 Baim DS, Wahr D, George B, et al. Randomized trial of a distal embolic protection device during percutaneous intervention of saphenous vein aortocoronary bypass grafts. Circulation 2002;105:1285-90.

66 Stone GW, Rogers C, Hermiller J. Randomized comparison of distal protection with a filter-based catheter and a balloon occlusion and aspiration system during percutaneous intervention of diseased saphenous vein aortocoronary bypass grafts. Circulation 2003; 108:548-53.

67 Izumi M, Tsuchikane E, Funamoto $M$, et al. Final results of the CAPAS trial. Am Heart J 2001;142:782-9.

68 Braun P, Stroh E, Heinrich KW. Rotablator versus cutting balloon for the treatment of long in-stent restenoses. J Invasive Cardiol 2002;14:291-6.

69 Bech GJW, de Bruyne B, Piljs NHJ, et al. Fractional flow reserve to determine appropriateness of angioplasty in moderate coronary angioplasty. Circulation 2001; 103:2928-34.

70 Pijls NH, Klauss V, Siebert U. Coronary pressure measurement after stenting predicts adverse events at follow-up: a multicenter registry. Circulation 2002; 105:2950-4

71 Cannon CP, Weintruab WS, Demopoulos LA. Invasive versus conservative strategies in unstable angina and non-Q-wave myocardial infarction following treatment with tirofiban: rationale and study design of the international TACTICS-TIMI 18 Trial. Treat angina with Aggrastat and determine cost of therapy with an invasive or conservative strategy. 
72 Bertrand ME, Simoons ML, Fox KA. Management of acute coronary syndromes in patients presenting without persistent ST-segment elevation. Eur Heart J 2002;23:1809-40.

73 Weaver WD, Simes RJ, Bertriu. A comparison of primary coronary angioplasty and intravenous thrombolytic therapy for acute myocardial infarction: a quantitative review. JAMA 1997;278:2093-8.

74 Stone GW, Grines CL, Browne KF. Predictors of in-hospital and 6-month outcome after acute myocardial infarction in the reperfusion era: the primary angioplasty in myocardial infarction (PAMI) trial. J Am Coll Cardio 1995:25:370-7.

75 Keeley EC, Boura JA, Grines C. Primary angioplasty versus intravenous thrombolytic therapy: a quantitative review of 23 randomised trials. Lancet 2003;361:13-20.

76 GUSTO Ilb Investigators. A clinical trial comparing primary coronary angioplasty with tissue plasminogen activator for acute myocardial infarction. The global use of strategies to open occluded coronary arteries in acute coronary syndromes (GUSTO Ilb). N Engl J Med 1997;336:1621-8.

77 Cannon CP, Gibson CM, Lambrew CT, et al. Relationship of symptom-onsetto-balloon time and door-to-balloon time with mortality in patients undergoing angioplasty for acute myocardial infarction. JAMA 2000;283:2941-7

78 Maillard $L$, Hamon $M$, Khalife $K$, et al. A comparison of systematic stenting and conventional balloon angioplasty during primary percutaneous transluminal coronary angioplasty for acute myocardial infarction. STENTIM2 Investigators. J Am Coll Cardiol 2000;35:1729-36.

79 Stone GW, Grines CL, Rothbaume D, et al. Analysis of the relative costs and effectiveness of primary angioplasty versus tissue-type plasminogen activator: the primary angioplasty in myocardial infarction (PAMI) trial. The PAMI Trial Investigators. J Am Coll Cardiol 1997;29:901-7.

80 Schömig A, Kastrati A, Dirschinger J. Coronary stenting plus platelet glycoprotein Ilb/llla blockade compared with tissue plasminogen activator in acute myocardial infarction. STOP-AMl study investigators. N Engl J Med 2000:343:385-91.

81 Neumann FJ, Kastrati A, Schmitt C. Effect of glycoprotein Ilb/llla receptor blockade with abciximab on clinical and angiographic restenosis rate after the placement of coronary stents following acute myocardial infarction. J Am Coll Cardiol 2000;35:915-21.

82 Grines CL, Topol EJ, Bates ER. Infarct vessel status after intravenous tissue plasminogen activator and acute coronary angioplasty: prediction of clinical outcome. Am Heart J 1988;1 15:1-7.

83 Ross AM, Coyne KS, Reiner JS, et al. A randomized trial comparing primary angioplasty with a strategy of short-acting thrombolysis and immediate planned rescue angioplasty in acute myocardial infarction: the PACT trial. PACT investigators. Plasminogen-activator angioplasty compatibility trial. J Am Coll Cardiol 1999;34:1954-62.

84 Juliard JM, Himbert D, Critofini P. A matched comparison of the combination of pre-hospital thrombolysis and standby rescue angioplasty with primary angioplasty. Am J Cardiol 1999;83:305-10.

85 Loubeyre C, Lefevre T, Louvard Y. Outcome after combined reperfusion therapy for acute myocardial infarction, combining pre-hospital thrombolysis with immediate percutaneous coronary intervention and stent. Eur Heart $J$ $2001 ; 22: 1128-35$

86 Montalescot G, Barragan P, Wittenberg O. Platelet glycoprotein Ilb/Illa inhibition with coronary stenting for acute myocardial infarction. The ADMIRAL trial. N Engl J Med 2001;344:1895-903.

87 Stone GW, Grines CL, Cox DA. Comparison of angioplasty with stenting, with or without abciximab, in acute myocardial infarction. The CADILLAC trial. N Engl J Med 2002;346:957-66.

88 Fernandez-Aviles F, Alonso JJ, Castro-Beiras A, et al. Primary optimal PCl versus facilitated intervention (tenecteplase plus stenting) in patients with ST elevated acute myocardial infarction: the GRACIA-2 randomised trial [abstract]. Circulation 2003;108:IV468.

89 Herrmann HC, Moliterno DJ, Ohman M, et al. Facilitation of early percutaneous coronary intervention after reteplase with or without abciximab in acute myocardial infarction (SPEED). J Am Coll Cardiol 2000;36:1489-96

90 Widimsky P, Groch L, Zelizko M, et al. Multicentre randomised trial comparing transport to primary angioplasty vs immediate thrombolysis vs combined strategy for patients with acute myocardial infarction presenting to a community hospital without a catheterisation laboratory: the PRAGUE study. Eur Heart J 2000;21:823-31.

91 Perez de Arenaza D, Taneja AK. Long distance transport for primary angioplasty vs immediate thrombolysis in acute myocardial infarction (PRAGUE-2 trial). Eur Heart J 2003;24:1798.

92 Moon JC, Kalra PR, Coats AJ. DANAMI-2: is primary angioplasty superior to thrombolysis in acute $\mathrm{MI}$ when the patient has to be transferred to an invasive centre? Int J Cardiol 2002;85:199-201.

93 Morice MC, Serruys PJ, de Sousa JE. A randomized comparison of a sirolimus-eluting stent with a standard stent for coronary revascularization. N Engl J Med 2002;346:1773-80.

94 Moses JW, Leon MB, Popma JJ, et al. Sirolimus-eluting stents versus standard stents in patients with stenosis in a native coronary artery. N Engl J Med 2003:349:1315-23.

95 Schofer J, Schluter M, Gershlick AH. Sirolimus-eluting stents for treatment of patients with long atherosclerotic lesions in small coronary arteries: doubleblind, randomised controlled trial (E-SIRIUS). Lancet 2003;362:1093-9.

96 Gershlick AH, De Scheerder I, Chevalier B, et al. Inhibition of restenosis with a paclitaxel-eluting coronary stent: The European evaluation of paclitaxel eluting stent (ELUTES) trial. Circulation 2004; 109:487-93.

97 Hong MK, Mintz GS, Lee CW. Paclitaxel coating reduces in-stent intima hyperplasia in human coronary arteries: a serial volumetric intravascula ultrasound analysis from the Asian paclitaxel-eluting stent clinical trial (ASPECT). Circulation 2003; 107:517-20

98 Colombo A, Drzewiecki J, Banning A. Randomized study to assess the effectiveness of slow- and moderate-release polymer-based paclitaxeleluting stents for coronary artery lesions. Circulation 2003; 108:788-94.

99 Stone GW, Ellis SG, Cox DA, et al. A polymer-based, paclitaxel-eluting stent in patients with coronary artery disease. N Engl J Med 2004;350:221-31.

100 Popma J, Heuser R, Suntharalingam M, et al. for the START Investigators. Late clinical and angiographic outcomes after use of ${ }^{90} \mathrm{Sr} /{ }^{90} \mathrm{Y}$ beta radiation for the treatment of in-stent restenosis. Results from the stents and radiation therapy (START) trial (abstract). J Am Coll Cardiol 2000;35.

101 Waksman R, Raizner A, Lansky A, et al. Beta radiation to inhibit recurrence of in-stent restenosis: study design, device and dosimetry details of the multicenter randomised double blind study (abstract). Circulation 2000; 102(suppl II):667.

102 Gershlick AH. Brachytherapy for de novo lesions: lessons from the BETACATH trial. Vasc Radiat Monit 2002:4:36-40.

103 Urban P, Serruys P, Baumgart D. A multicentre European registry of intraluminal coronary beta brachytherapy. Eur Heart J 2003;24:604-12.

104 Grise MA, Massulo V, Jani S. Five-year clinical follow-up after intracoronary radiation: results of a randomized clinical trial. Circulation 2002; 105:2737-40.

105 Koning R, Khalife K, Commeau P, et al. The BESMART (BeStent in small arteries): in-hospital clinical and angiographic results [abstract]. Circulation 1999; 100:1503.

106 Kastrati A, Schoming A, Dirschinger J, et al. A randomised trial comparing stenting with balloon angioplasty in small vessels in patients with coronary artery disease. Circulation 2000;102:2593-8.

107 Schalii M, Doucet S, Hilton D, et al. The SISA study: a randomised comparison of balloon angioplasty and stent to prevent restenosis in small arteries: 6 month angiographic and 12 month clinical outcome [abstract]. Circulation 2000;18:11663.

108 Mehilli J, Kastrati A, Dirschinger J. Comparison of stenting with balloon angioplasty for lesions of small coronary vessels in patients with diabetes mellitus. Am J Med 2002;112:13-8.

109 Park SJ, Park SW, Hong Mk, et al. Stenting of unprotected left main coronary artery stenoses: immediate and late outcome. J Am Coll Cardiol 1998;31:37-42.

110 Ellis SG, Tamai H, Nobuyoshi M, et al. Contemporary percutaneous treatment of unprotected left main coronary stenoses: initial results from a multicenter registry analysis 1994-1996. Circulation 1997;96:3867-72.

111 Black A, Cortina R, Bossi I, et al. Unprotected left main coronary artery stenting: correlates of midterm survival and impact of patient selection. J Am Coll Cardiol 2001:37:832-8.

112 Brueren BR, Ernst JM, Suttorp MJ. Long term follow up after elective percutaneous coronary intervention for unprotected non-bifurcational left main stenosis: is it time to change the guidelines? Heart 2003;89:1336-9.

113 Kelley MP, Klugherz BD, Hashemi SM. One-year clinical outcomes of protected and unprotected left main coronary artery stenting. Eur Heart $J$ 2003;24:1554-9

114 Lee CH, Degertekin M, van Domburg RT. Impact of different anatomical patterns of left main coronary stenting on long-term survival. Am J Cardiol 2003;92:718-20

115 Lefevre T, Louvard Y, Morice MC, et al. Stenting of bifurcation lesions: classification, treatments, and results. Catheter Cardiovasc Interv 2000;49:274-83.

116 Costa $\mathbf{R}$, Joyal M, Harel F. Treatment of bifurcation in-stent restenotic lesions with beta radiation using strontium 90 and sequential positioning pullback technique: procedural details and clinical outcomes. J Invasive Cardiol 2003; 15:469-73

117 Colombo A, Stankovic G, Orlic D. Modified T-stenting technique with crushing for bifurcation lesions: immediate results and 30-day outcome. Catheter Cardiovasc Interv 2003;60:145-51

118 Toutouzas K, Stankovic G, Takagi T. A new dedicated stent and delivery system for the treatment of bifurcation lesions: preliminary experience. Catheter Cardiovasc Interv 2003;58:34-42.

119 Serruys PW, Unger F, van Hout BF. The ARTS study larterial revascularization therapies study). Semin Interv Cardiol 1999;4:209-19.

120 Rodriguez A, Bernardi V, Navia J. Argentine randomised study: coronary angioplasty with stenting versus coronary bypass surgery in patients with multiple vessel disease (ERACI-II). J Am Coll Cardiol 2001;37:51-8.

121 The SOS Investigators. Coronary artery bypass surgery versus percutaneous coronary intervention with stent implantation in patients with multi-vesse disease. The SOS Investigators. Lancet 2002;360:965-70.

122 de Feyter PJ, Serruys PW, Unger F. Bypass surgery versus stenting for the treatment of multivessel disease in patients with unstable angina compared with stable angina. Circulation 2002;105:2367-72.

123 Cisowski M, Morawski W, Drzewiecki J, et al. Integrated minimally invasive direct coronary artery bypass (MIDCAB) grafting and angioplasty for coronary artery revascularization. Heart Surg Forum 2002;5(suppl 4):S282-95.

124 Riess FC, Bader R, Kremer P. Coronary hybrid revascularization from January 1997 to January 2001: a clinical follow-up. Ann Thorac Surg 2002;73:1849-55.

125 Drenth DG, Winter JB, Veeger NJ. Minimally invasive coronary artery bypass grafting versus percutaneous transluminal coronary angioplasty with stenting in isolated high-grade stenosis of the proximal left anterior descending coronary artery: six months' angiographic and clinical follow-up of a prospective randomized study. J Thorac Cardiovasc Surg 2002;124:130-5 
126 Shaw RE, Anderson HV, Brindis RG, et al. Development of a risk adjustment mortality model using the American College of Cardiology-National Cardiovascular Data Registry (ACC-NCDR) experience: 1998-2000. Am Coll cardiol 2002;39:1104-2.

127 Chan A, Chew DP, Bhatt DL. Long-term mortality benefit with the combination of stents and abciximab for cardiogenic shock complicating acute myocardial infarction. Am J Cardiol 2002;89:132-6.

128 Hochman JS, Sleeper LA, Webb JG. Early revascularization in acute myocardial infarction complicated by cardiogenic shock. SHOCK

Investigators. Should we emergently revascularize occluded coronaries for cardiogenic shock. N Engl J Med 1999;341:625-34.

129 Webb JG, Lowe AM, Sanborn TA. Percutaneous coronary intervention for cardiogenic shock in the SHOCK trial. J Am Coll Cardiol 2003;42:1380-6.

130 Puma JA, Sketch MH Jr, Tcheng JE. Percutaneous revascularization of chronic coronary occlusions: an overview. J Am Coll Cardiol 1995;26:1-11

131 Ivanhoe RJ, Weintraub WS, Douglas JS Jr, et al. Percutaneous translumina coronary angioplasty of chronic total occlusions: primary success, restenosis, and long-term clinical follow-up. Circulation 1992;85:106-15.

132 Suero JA, Marso SP, Jones PG, et al. Procedural outcomes and long-term survival among patients undergoing percutaneous coronary intervention of a chronic total occlusion in native coronary arteries: a 20-year experience. J Am Coll Cardiol 2001;38:409-14.

133 Hoher M, Wohrle J, Grebe OC, et al. A randomized trial of elective stenting after balloon recanalization of chronic total occlusions. J Am Coll Cardiol 1999;34:722-9.

134 Buller CE, Dzavik V, Carere RG, et al. Primary stenting versus balloon angioplasty in occluded coronary arteries: the total occlusion study of Canada (TOSCA). Circulation 1999;100:236-42.
135 Sirnes PA, Golf S, Myreng Y, et al. Stenting in chronic coronary occlusion (SICCO): a randomised controlled trial of adding a stent implantation after successful angioplasty. J Am Coll Cardiol 1996;28:1444-51

136 Noguchi T, Miyazaki S, Morii I. Percutaneous transluminal coronary angioplasty of chronic total occlusions: determinants of primary success and long-term clinical outcome. Catheter Cardiovasc Interv 2000;49:258-64.

137 Iliadis EA, Zaacks SM, Calvin JE. The relative influence of lesion length and other stenosis morphologies on procedural success of coronary intervention. Angiology 2000;51:39-52.

138 Kinoshita I, Katoh O, Nariyama J, et al. Coronary angioplasty of chronic total occlusions with bridging collateral vessels: immediate and follow-up outcome from a large single-center experience. J Am Coll Cardiol 1995;26:409-15.

139 Tan KH, Sulke N, Taub NA. Determinants of success of coronary angioplasty in patients with a chronic total occlusion: a multiple logistic regression model to improve selection of patients. Br Heart J 1993;70:126-31.

140 Olivari Z, Rubartelli P, Piscione F, et al. Immediate results and one-year clinical outcome after percutaneous coronary interventions in chronic total occlusions: data from a multicenter, prospective, observational study (TOAST-GISE). J Am Coll Cardiol 2003;41:1672-8.

$141 \mathrm{Ng} \mathrm{W}$, Chen WH, Lee PY, et al. Initial experience and safety in the treatment of chronic total coronary occlusions with a new optical coherent reflectometry-guided radiofrequency ablation guidewire. Am J Cardiol 2003;92:732-4.

142 Whitbourn RJ, Cincotta M, Mossop P, et al. Intraluminal blunt microdissection for angioplasty of coronary chronic total occlusions. Catheter Cardiovasc Interv 2003;58:194-8. 